\title{
REVISIÓN PRELIMINAR DE LAS ESPECIES DEL GÉNERO BRUEELIA KÉLER, 1936 (PHTHIRAPTERA, PHILOPTERIDAE) PARÁSITAS DE ICTERINAE (AVES, PASSERIFORMES, FRINGILLIDAE)
}

\author{
A.C. Cicchino* y D.C. Castro*
}

RESUMEN

Las especies del género Brueelia que parasitan distintos táxones de Icterinae presentan un conjunto de características somáticas que permiten discriminarlas en dos agrupamientos informales de especies, aquí denominados grupo picturata y grupo ornatissima, este último subdividido en dos: subgrupo cela y subgrupo amazonae. En esta aportación nos ocupamos de la caracterización morfológica de los citados agrupamientos y de la descripción o notas taxonómicas de las veintidós especies hasta hoy conocidas que incluimos en el grupo picturata y en el grupo ornatissima: Brueelia picturata (Osborn, 1896) (ex Sturnella magna), B. pseudopicturata Cicchino, 1986 (ex Sturnella neglecta), B. boae sp. n. (ex Sturnella l. loyca), B. cela Stafford, 1943 (ex Cacicus c. cela), B. virgata (Kellogg, 1899) (ex Amblycercus h. holosericeus), B. solitaria Cicchino, 1988 (ex Cacicus solitarius), B. decumana sp. n. (ex Psarocolius decumanus maculosus), B. abrupta (Osborn, 1896) (hospedador desconocido), B. ornatissima (ex Agelaius p. phoeniceus), B. mirabile Carriker, 1963 (ex Scaphidura o. oryzivora), B. ruficapilla Cicchino, 1990 (ex Agelaius ruficapillus), B. mauroi sp. n. (ex Tangavius aeneus), $B$. emersoni sp. n. (ex Euphagus carolinus), B. marcoi sp. n. (ex Curaeus c. curaeus), B. trinidadensis sp. n. (ex Molothrus bonariensis minimus), B. americana sp. n. (ex Molothrus a. ater), B. bonariensis sp. n. (ex Molothrus b. bonariensis), B. badia sp. n. (ex Molothrus b. badius), B. flinti sp. n. (ex Cassidix m. mexicanus), B. mimas sp. n. (ex Pseudoleistes virescens), y finalmente se discute el status taxonómico y las probables afinidades de $B$. sallei Carriker, 1963, $B$. amazonae Stafford, 1943, B. latiuscula (Kellogg \& Chapman, 1899) y B. xanthocephali (Osborn, 1896).

Palabras clave: Brueelia, redescripciones, nuevas especies, Icterinae.

\section{SUMMARY}

Preliminary revision of the species of the genus Brueelia Kéler, 1936 (Phthiraptera, Philopteridae) parasiting Icterinae (Aves, Passeriformes, Fringillidae)

A number of distinctive somatic features permit to divide the Brueelia-species parasitic on different taxa of Icterinae in two major informal species-groups here named picturata- group and ornatissima-group, and the latter subdivided in the cela-subgroup and amazonae-subgroup. In this paper, we deal with the characterization of these groups and subgroups along with the description or taxonomic notes of the twenty two species of both groups hitherto known to parasitize Icterinae birds: B. picturata (Osborn, 1896) (ex Sturnella magna), B. pseudopicturata Cicchino, 1986 (ex Sturnella neglecta), B. boae sp. n. (ex Sturnella l. loyca), B. cela Stafford, 1943 (ex Cacicus c. cela), B. virgata (Kellogg, 1899) (ex Amblycercus h. holosericeus), B. solitaria Cicchino, 1988 (ex Cacicus solitarius), B. decumana sp. n. (ex Psarocolius decumanus maculosus), B. abrupta (Osborn, 1896) (unknown host), B. ornatissima (ex Agelaius phoeniceus), B. ruficapilla (ex Agelaius ruficapillus), B. mirabile (ex Scaphidura o. oryzivora), B. mauroi sp. n. (ex Tangavius aeneus), B. emersoni sp. n. (ex Euphagus carolinus), B. marcoi sp. n. (ex Curaeus c. curaeus), B. trinidadensis sp. n. (ex Molothrus bonariensis minimus), B. americana sp. n. (ex Molothrus a. ater), B. bonariensis sp. n. (ex Molothrus b. bonariensis), $B$. badia sp. n. (ex Molothrus b. badius), B. oxypyga (ex Amblyramphus holosericeus), B. flinti sp. n. (ex Cassidix m. mexicanus), and B. mimas sp. n. (ex Pseudoleistes virescens), discussing the taxonomic status and probable affinities of B. sallei Carriker, 1963, B. amazonae Stafford, 1943, B. latiuscula (Kellogg \& Chapman, 1899) and B. xanthocephali (Osborn, 1896).

Key words: Brueelia, redescriptions, new species, Icterinae.

* Facultad de Ciencias Naturales y Museo de La Plata, 1900 La Plata, Provincia de Buenos Aires, Argentina. Investigadores del CONICET. 


\section{Introducción}

Hasta el presente se han descrito 13 especies del género Brueelia Keler, 1936 como parásitos de Fringillidae de la subfamilia Icterinae (en el sentido de Sibley et al., 1988), faltando un estudio de revisión, el que nos proponemos comenzar con la presente contribución.

La totalidad de las especies que parasitan esta singular subfamilia de Passeriformes, exclusivamente americana, presentan características somáticas particulares que permiten discriminarlas en dos grupos y dos subgrupos informales de especies razonablemente bien definidos. En esta aportación, nos ocuparemos de la caracterización de estos agrupamientos y de la redescripción o notas críticas de las 22 especies hasta hoy halladas (11 conocidas y 11 nuevas), parásitas de la subfamilia Icterinae de los Fringillidae: Brueelia picturata (Osborn, 1896) (ex Sturnella magna), B. pseudopicturata Cicchino, 1986 (ex Sturnella neglecta), B. boae sp. n. (ex Sturnella l. loyca), B. cela Stafford, 1943 (ex Cacicus c. cela), B. virgata (Kellogg, 1899) (ex Amblycercus $h$. holosericeus), B. solitaria Cicchino, 1988 (ex Cacicus solitarius), B. decumana sp. n. (ex Psarocolius decumanus maculosus), B. abrupta (Osborn, 1896) (hospedador desconocido), B. ornatissima (ex Agelaius p. phoeniceus), B. mirabile Carriker, 1963 (ex Scaphidura o. oryzivora), B. ruficapilla Cicchino, 1990 (ex Agelaius ruficapillus), B. mauroi sp. n. (ex Tangavius aeneus), B. emersoni sp. n. (ex Euphagus carolinus), B. marcoi sp. n. (ex Curaeus c. curaeus), B. trinidadensis sp. n. (ex Molothrus bonariensis minimus), B. americana sp. n. (ex Molothrus a. ater), B. bonariensis sp. n. (ex Molothrus b. bonariensis), B. badia sp. n. (ex Molothrus b. badius), B. flinti sp. n. (ex Cassidix $m$. mexicanus), B. mimas sp. n. (ex Pseudoleistes virescens), y finalmente se discute el estatus taxonómico y las probables afinidades de B. sallei Carriker, 1963, B. amazonae Stafford, 1943, B. latiuscula (Kellogg \& Chapman, 1899) y B. xanthocephali (Osborn, 1896).

\section{Material y Métodos}

Los ejemplares estudiados procedentes de la República Argentina fueron colectados por nosotros a partir de sus respectivos hospedadores. Estos últimos fueron abatidos utilizando armas de fuego a munición, inmediatamente envueltos en bolsas de género y éstas puestas en bolsas de nylon conteniendo acetato de etilo. En el laboratorio realiza- mos la extracción, recuento y verificación de los sitios de postura de cada especie en cada individuo hospedador.

Los ejemplares se procesaron con las técnicas microscópicas corrientes para estos insectos, examinándose al microscopio óptico y efectuándose las comparaciones cuali y cuantitativas de los distintos elementos somáticos diagnósticos. Los dibujos fueron confeccionados por nosotros con cámara clara, tomándose las medidas sobre los ejemplares montados a través de un ocular adecuadamente calibrado. Las fotografías fueron tomadas utilizando un microscopio Wild M-21 con aparato de fotografía, empleándose película de 32 ASA.

Las medidas corporales utilizadas en las descripciones (expresadas en $\mathrm{mm}$ ) son las siguientes: longitud máxima de la cabeza; anchura preantenal, tomada a la altura de la seta preantenal; anchura temporal; longitud total del protórax; anchura máxima del protórax; longitud total del pterotórax; anchura máxima del pterotórax; longitud máxima del abdomen; anchura máxima del abdomen, medida a nivel del segmento $\mathrm{V}$, y longitud total del cuerpo.

Para la nomenclatura de las regiones cefálicas seguimos a Symmons (1952) (Fig. 42), y para aquella de sus setas a Clay (1951). En todos los casos, se describe la extensión de la pigmentación y su tonalidad para todas las carenas y suturas cefálicas, como característica auxiliar en la diferenciación específica, sin repetir aquellas que son propias de los grupos o subgrupos de especies.

En la descripción de los apodemas pro y pterotorácicos se considera unicamente la distribución y tonalidad de su pigmentación (Fig. 1).

En la descripción de la quetotaxia abdominal se ha utilizado la siguiente nomenclatura (Fig. 2):

Setas paratergales: se encuentran en número de una o dos en cada paraterguito a partir del III. Cuando existen dos en cada uno, éstas son de distinta longitud.

Setas postespiraculares principales: setas medianas a largas, que se encuentran a razón de una por cada hemiterguito, siempre presentes en los terguitos VI y VII en ambos sexos. En los machos pueden estar presentes a partir del IV, y en las hembras a partir del V.

Setas postespiraculares accesorias: setas cortas a medianas que se encuentran a razón de una por cada hemiterguito, en el VI y VII (en algunas especies también en $\mathrm{V}$ ) únicamente en los machos.

Setas tergales posteriores: setas cortas a medianas que se encuentran a razón de una a cuatro por cada hemiterguito, en el VI y VII (en algunas especies también en $\mathrm{V}$ ) únicamente en los machos. 
Tabla I.- Diferencias entre los grupos picturata y ornatissima.

\section{GRUPO PICTURATA}

- Areas genal y subgenal, y suturas hipostomal, occipital y postoccipital desprovistas de pigmento.

- Borde pulvinar de la sutura clipeofrontal siempre carente de mácula.

- Terguitos II-VIII desprovistos de marginaciones pardas.

- Placa gular entera, con pigmentación casi uniforme.

- Placas subgenitales de ambos sexos enteras, pigmentadas casi uniformemente.

- Paraterguitos muy anchos, parduzcos.

- Terguito VIII de las hembras desprovisto de seta sutural.

- Genitales masculinos con parámeros largamente subtriangulares.

Setas suturales: setas cortas que se encuentran en el margen interno de cada hemiterguito, en el VI y VII (en algunas especies también en IV y/o V) únicamente en los machos. La seta larga ubicada en el margen interno del hemiterguito VIII de las hembras de las especies incluidas en el grupo ornatissi$m a$, puede considerarse también una seta sutural de gran longitud.

El depósito de los materiales estudiados está indicado por las siguientes siglas: MLP: colección Museo de La Plata, Buenos Aires, Argentina; NMNH: National Museum of Natural History, Smithsonian Institution, Washington, USA; KCE: colección Kary C. Emerson, Sanibel, Florida, USA.

\section{Tratamiento Sistemático}

Como ya hemos puntualizado, las especies de este género que parasitan Passeriformes Oscinos de la subfamilia Icterinae, presentan un conjunto de características somáticas que permiten diferenciarlas en dos agrupamientos informales de especies, aqui denominados grupo picturata y grupo ornatissima, este ultimo a su vez subdividido en subgrupo cela y subgrupo amazonae, cuyas características se muestran en la Tabla I.

A continuación nos ocuparemos de la descripción y notas críticas de las cuatro especies del grupo picturata y las 21 del grupo ornatissima.
Table I.- Differences between picturata and ornatissima groups.

\section{GRUPO ORNATISSIMA}

- Areas genal y subgenal, suturas hipostomal y postoccipital pigmentadas.

- Borde pulvinar de la sutura frontoclipeal con una mácula (subgrupo amazonae) o carente de ella o bien ésta es muy difusa (subgrupo cela).

- Terguitos II-VIII, o por lo menos algunos de ellos, marginados de parduzco.

- Placa gular fenestrada y frecuentemente con su extremo apical no contactando con el basal.

- Placas subgenitales de ambos sexos siempre fenestradas.

- Paraterguitos nunca anchos, frecuentemente con tinte negruzco.

- Terguito VIII de las hembras siempre provisto de una seta sutural larga.

- Genitales masculinos con parámeros fuertemente cóncavos en su borde externo, nunca subtriangulares.

\section{GRUPO PICTURATA}

Brueelia picturata (Osborn, 1896)

(Figs. 1 a 4, 24, 26, 30, 33, 35 y 38)

Nirmus picturatus Osborn, 1896. Bull. U.S. Dept. Agric. (Bur. Entomol.) (n.s.), 5: 226-227.

Degeeriella picturata Geist, 1935. Ohio J. Sci., 21(6): 509.

Bizarrifrons picturata: Eichler, 1938. Zool. Anz., 124(9/10): 233-234.

Brüelia picturata: Hopkins \& Clay, 1952. Checklist: 60; Carriker, 1954. Florida Entomol., 37(4): 199; Emerson, 1960. Proc. Biol. Soc. Washington, 73: 161.

Brueelia picturata: Emerson, 1972 Checklist, Pt. I: 32; pt. IV: 207.

Brueelia picturata Teel et al., 1988. J. Med. Entomol., 25(1): 37-37 (partim).

MATERIAL EXAMINADO: $10^{7}$ y $1 \%$ ex Sturnella magna argutula Bangs, 1899, Lyman, Miss., 1-V-1941 G.G. Rolawer col. (KCE); 2 ᄋ $\%$ ex Tangavius aeneus (Wagler, 1829) Alapaha, Georgia, USA, 30-X-1935 (KCE), interpretado como caso de transgresión parasitaria.

\section{REDESCRIPCIÓN:}

Macho: aspecto general como en la figura 2. Cabeza anchamente cordiforme; borde preantenal muy convexo; carena marginal oscurecida hacia el lado interno y hialina hacia el externo; son visibles las improntas de inserción de los músculos cibariales. Carenas temporales oscurecidas hacia su mitad interna. Margen nodal de la sutura clípeofrontal fuertemente ennegrecido. Apodemas protorácicos relativamente angostos, siendo los pterotorácicos más desarrollados. Terguitos abdominales pobremente pigmentados; VII con dos setas tergales pos- 


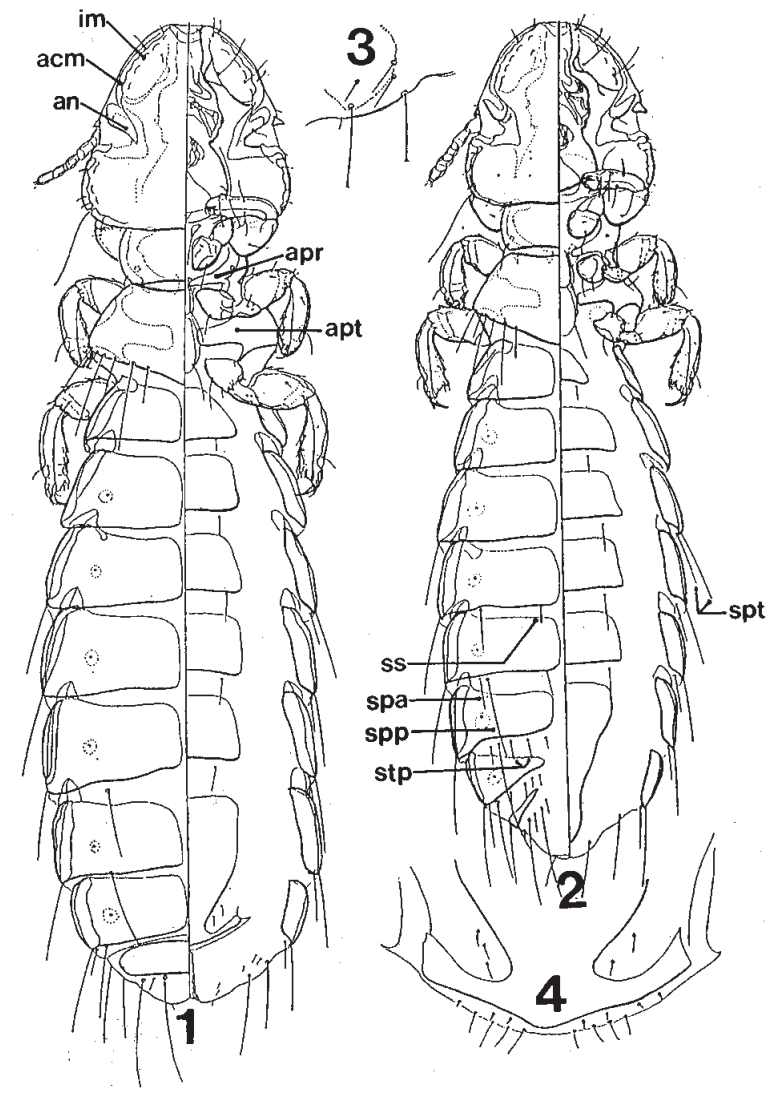

Figs. 1-4.- Brueelia picturata (Osborn, 1896): 1) hembra, 2) macho, 3 y 4) gonapófisis y vulva femeninas. Abreviaturas: apr: apodema protorácico; apt: apodema pterotorácico; $\mathbf{c m}$ : carena marginal; im: impresiones de los músculos cibariales; ss: seta sutural; spa: seta postespiracular accesoria; spp: seta postespìracular principal; spt: setas paratergales; stp: setas tergales posteriores.

Figs. 1-4.- Brueelia picturata (Osborn, 1896): 1) female, 2) male, 3 and 4) female vulva and gonapophysis. Abbreviations: apr: prothoracic apodema; apt: pterothoracic apodema; $\mathbf{c m}$ : marginal carina; im: impression of cybarial muscles; ss: sutural seta; spa: postspiracular accesory seta; spp: postspiracular principal seta; spt: paratergal setae; stp: posterior tergal setae.

teriores; resto como en la figura 2. En VII puede haber una seta postespiracular accesoria supernumeraria. Quetotaxia paratergal: II-III, 0; IV-VII, 2. Genitalia: placa basal relativamente ancha (Fig. 24); parámeros robustos, escleritos laterales del complejo endomeral con 2-4 rugosidades en su margen posterior; longitud máxima 0,158 , anchura máxima 0,066 .

Hembra: como en la figura 1. Aspecto general semejante al macho, difiriendo en tamaño, proporciones, terminalia y quetotaxia abdominal. Vulva
(Fig. 4): 3-4 setas espiniformes y cuatro más delgadas a cada lado. Placa subgenital (Fig. 26) con 2-3 setas a cada lado. Gonapófisis (Fig. 3) con dos setas delgadas. Quetotaxia paratergal igual a la del macho.

MEDidAS CORPORALES:

$\begin{array}{lrc} & \text { Macho } & \text { Hembras } \\ \text { Longitud de la cabeza } & 0,375 & 0,412 \\ \text { Anchura preantenal } & 0,315 & 0,345-0,346 \\ \text { Anchura temporal } & 0,375 & 0,397-0409 \\ \text { Longitud del protórax } & 0,135 & 0,150-0,157 \\ \text { Anchura del protórax } & 0,223 & 0,240-0,247 \\ \text { Longitud del pterotórax } & 0,180 & 0,180-0,210 \\ \text { Anchura del pterotórax } & 0,334 & 0,360-0,371 \\ \text { Longitud del abdomen } & 1,020 & 1,192-1,260 \\ \text { Longitud total } & 1,672 & 1,917-1,964\end{array}$

HOSPEDADOR TIPO: Sturnella magna magna (Linné, 1758).

OtRos HOSPEDADORES: Sturnella magna argutula Bangs, 1899.

OBSERVACIONES: Su descripción original no contiene ilustraciones, y pese a ser bastante pormenorizada, no permite en la actualidad una identificación inequívoca de esta especie. Aún así, se trata de una especie típica de su hospedador en América del Norte, existiendo citas y registros de varias localidades.

Debe hacerse notar que, de acuerdo con Emerson (1960: 161) el material tipo de esta especie no ha podido ser localizado hasta el presente.

Se trata de una especie muy semejante a $B$. pseudopicturata Cicchino, 1986 y B. boae sp. n., y los caracteres que permiten separarla de ella se analizarán al tratar aquellas especies.

\section{Brueelia pseudopicturata Cicchino, 1986}

(Figs. 5 a 9 y 32 )

Brueelia pseudopicturata Cicchino, 1986. Rev. Soc. Entomol. Arg., 44(1): 85-87, figs 1-6.

Brueelia picturata Teel et al., 1988. J. Med. Entomol., 25(1): 36-37 (partim).

Material EXAMINADO: Holotipo $0^{7}$ y Alotipo $ᄋ$, Enterprise, Oregon, USA, 29-I-1932, S.G. Jewett Jr.; Paratipo o", Adel., Oregon, 9-II-1932, S.G. Jewett Jr. (NMNH).

\section{REDESCRIPCIÓN:}

Macho: aspecto general como en la figura 5. Cabeza oval; borde preantenal ligera y uniformemente convexo. Carena marginal muy oscurecida en su mitad interna (extendiéndose la pigmentación algo hacia el interior cefálico), hialina en su mitad 


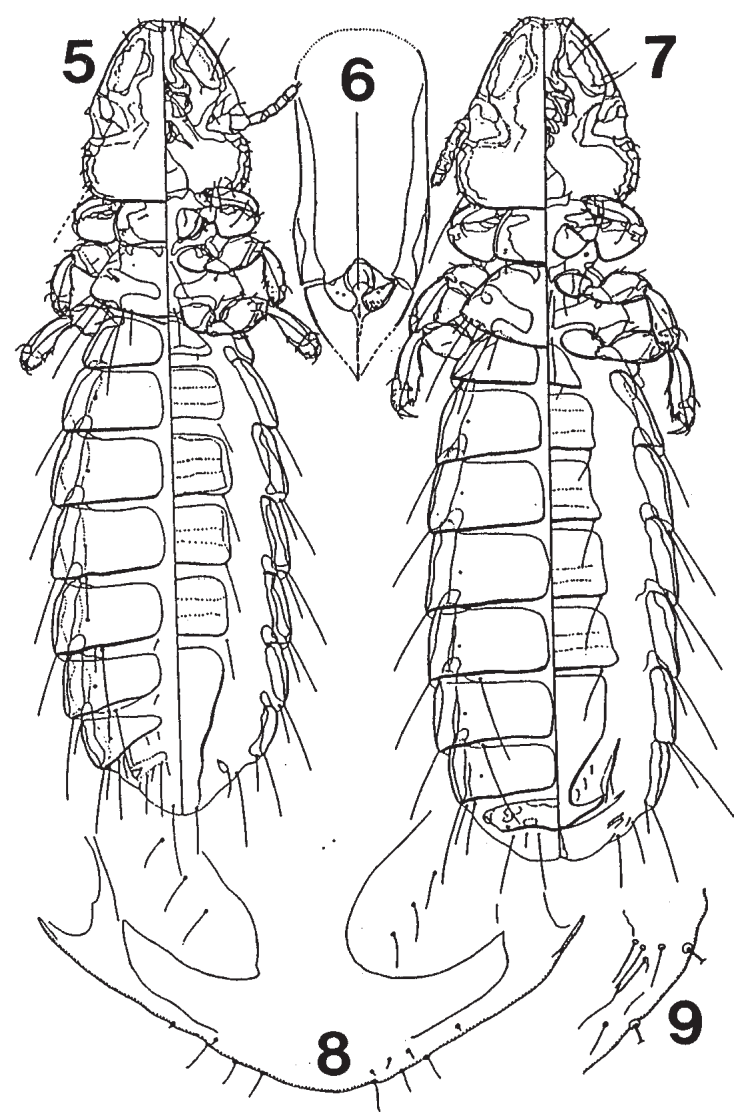

Figs. 5-9.- Brueelia pseudopicturata Cicchino, 1986: 5) macho, 6) genitalia masculina, 7) hembra, 8 y 9) gonapófisis y vulva femeninas.

Figs. 5-9.- Brueelia pseudopicturata Cicchino, 1986: 5) male, 6) male genitalia, 7) female, 8 and 9) female vulva and gonapophysis.

externa. Improntas de inserción de los músculos cibariales bien visibles. Área nodal de la sutura frontoclipeal fuertemente pigmentada. Apodemas protorácicos relativamente angostos, siendo los pterotorácicos más desarrollados. Terguitos prácticamente despigmentados. Ester-nitos parduzcos, enteros, con su área medial algo más clara. Quetotaxia paratergal: II, 0; III, 1; IV-VII, 2. Quetotaxia tergal: seta postespiracular mediana en $\mathrm{V}$, largas en VI-VII, setas postespiraculares accesorias medianas en VI-VII. El único ejemplar no posee setas tergales posteriores en VII. Genitalia (Fig. 6) con placa basal alargada, parámeros no claramente visibles en su totalidad debido a residuos de material en el tubo digestivo, pero aparecen como muy similares a los de B. picturata; escleri- tos laterales del complejo endomeral con margen posterior provisto de unos cinco pequeños tubérculos semejantes entre sí.

Hembra: como en la figura 7. Aspecto general y "hábitus" semejantes a los del macho, difiriendo en tamaño, proporciones, terminalia y quetotaxia tergal. Vulva (Fig. 8) con 3-4 setas espiniformes y 34 delgadas y más largas a cada lado. Gonapófisis (Fig. 9) con 2-3 setas. Placa subgenital con 2-3 setas a cada lado. Quetotaxia paratergal igual a la del macho.

$\begin{array}{lcc}\text { MEDIDAS CORPORALES: } & & \\ & \text { Machos } & \text { Hembras } \\ \text { Longitud de la cabeza } & 0,380 & 0,515 \\ \text { Anchura preantenal } & 0,320 & 0,332 \\ \text { Anchura temporal } & 0,356 & 0,380-0,388 \\ \text { Longitud del protórax } & 0,136 & 0,142-0,172 \\ \text { Anchura del protórax } & 0,219 & 0,225-0,228 \\ \text { Longitud del pterotórax } & 0,154 & 0,225 \\ \text { Anchura del pterotórax } & 0,332 & 0,350-0,380 \\ \text { Longitud del abdomen } & 1,091 & 1,162-1,322 \\ \text { Anchura del abdomen } & 0,516 & 0,528-0,546 \\ \text { Longitud total } & 1,732 & 1,850-2,034\end{array}$

Probable hosPEDADOR tiPO: Sturnella neglecta Audubon, 1844.

OBSERVACIONES: especie muy próxima a $B$. picturata (Osborn, 1896), de la que difiere por la forma de la cabeza, sobre todo la región preantenal (confrontar figuras 32 y 33), genitales masculinos y por tener setas paratergales en III.

La estrecha afinidad existente entre estas dos especies de parásitos supone un común origen historicamente no demasiado lejano, que se correlaciona con el propio de sus respectivos hospedadores, $S$. magna y $S$. neglecta, a los cuales puede aplicarse el concepto de "superespecie" (Short, 1968: 26-27) ya definido con propiedad por Amadon (1966): “The concept 'superspecies', as applied to a monophyletic group of allopatric or nearly allopatric taxa that are known or believed to have evolved to the species level..." (resumen encabezando la pag. 245).

Brueelia boae sp. $\mathrm{n}$.

(Figs. 10 a 13, 25, 27-28, 31, 36 y 39)

Material eXAminado: Holotipo $0^{x}$, Alotipo $q$ y $40^{x} 0^{x}, 85 q \circ$ y 24 ninfas, Paratipos, ex Sturnella loyca loyca (Molina, 1782), Santa Rosa, Prov. La Pampa, Argentina (A.C. Cicchino, KCE, NMNH, MLP); $60^{\pi} 0^{x}$ y 4 \& $\%$ mismo hospedador, Huilmo, Pumitaqui, Coquimbo, Chile, 24-VI-1981, M.A. Marín (KCE). 


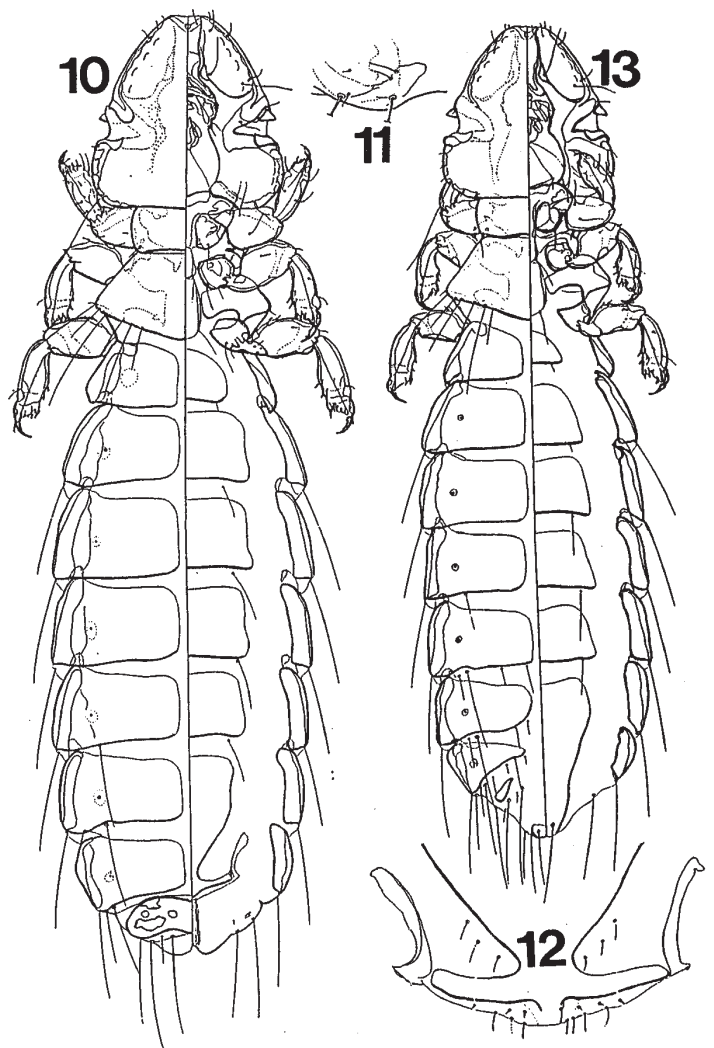

Figs. 10-13.- Brueelia boae sp. n.: 10) hembra, 11 y 12) gonapófisis y vulva femeninas, 13) macho.

Figs. 10-13.- Brueelia boae sp. n.: 10) female, 11 and 12) female gonapophysis and vulva, 13) male.

\section{DESCRIPCIÓN:}

Macho: aspecto general como en la figura 10. Cabeza subcordiforme; borde preantenal moderadamente convexo. Carena marginal con su borde interno oscurecido, y el extremo hialino; improntas de inserción de los músculos cibariales bien visibles. Carenas temporales oscurecidas en su mitad interna, y la externa hialina. Margen nodal de la sutura clipeofrontal muy ennegrecido. Apodemas protorácicos muy fuertes, lo mismo que los pterotorácicos. Terguitos abdominales pobremente pigmentados. Seta postespiracular mediana a larga presente en V-VII; seta tergal posterior corta a mediana presente en VI-VIII (VIII a veces con dos). Quetotaxia paratergal: II, 0; III-VII, 1. Genitalia: placa basal algo angostada hacia su mitad superior; parámeros largos y gráciles; escleritos laterales del complejo endomeral con 4-6

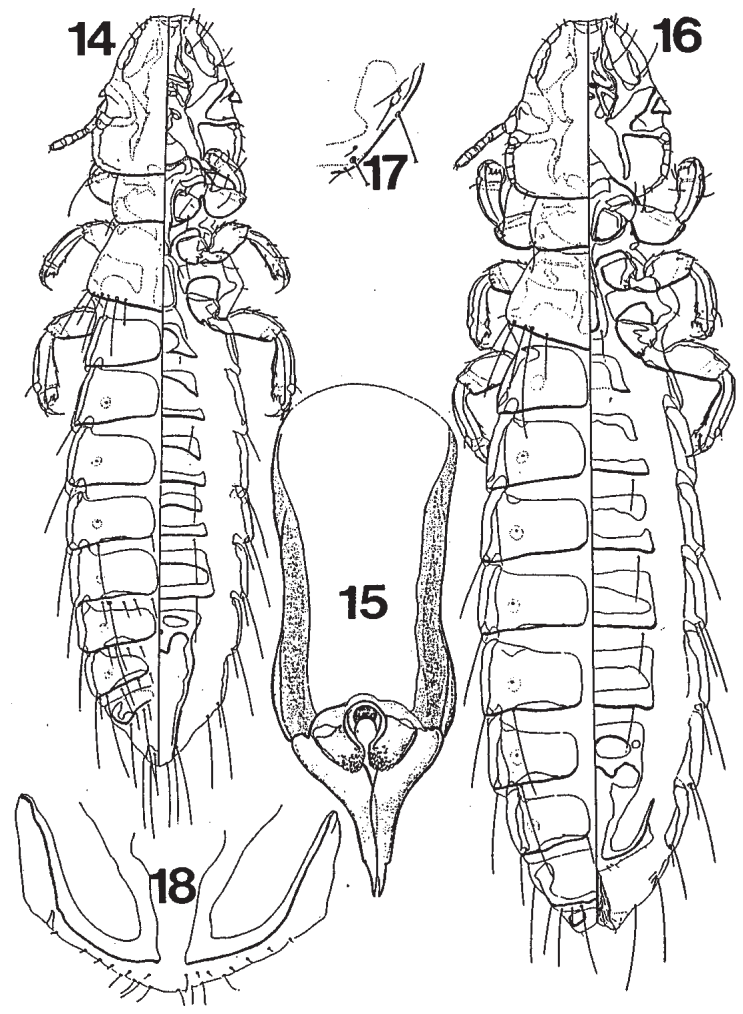

Figs. 14-18.-Brueelia decumana sp. n.: 14) macho, 15) genitalia masculina, 16) hembra, 17) y 18) gonapófisis y vulva femeninas.

Figs. 14-18.-Brueelia decumana sp. n.: 14) male, 15) male genitalia, 16) female, 17 and 18) female gonapophysis and vulva.

rugosidades en su margen posterior (Fig. 25); longitud máxima 0,126-0,144, anchura máxima 0,0620,063 .

Hembra: como en la figura 10. Aspecto general semejante al del macho, difiriendo en tamaño, medidas, terminalia y quetotaxia abdominal; quetotaxia paratergal igual a la del macho. Vulva (Fig. 12): con tres setas espiniformes en una hilera superior (a las que suelen sumarse una seta delgada), y una hilera inferior de 2-4 setas delgadas más largas a cada lado. Gonapófisis (Fig. 11) con dos setas más o menos delgadas. Pigmentación del terguito IX característica. Placa subgenital como en las figuras 27 y 28.

MEDIDAS CORPORALES:

Longitud de la cabeza

Machos

$0,375-0,386$

Hembras

Anchura preantenal
$0,412-0,420$

$0,343-0,345$ 


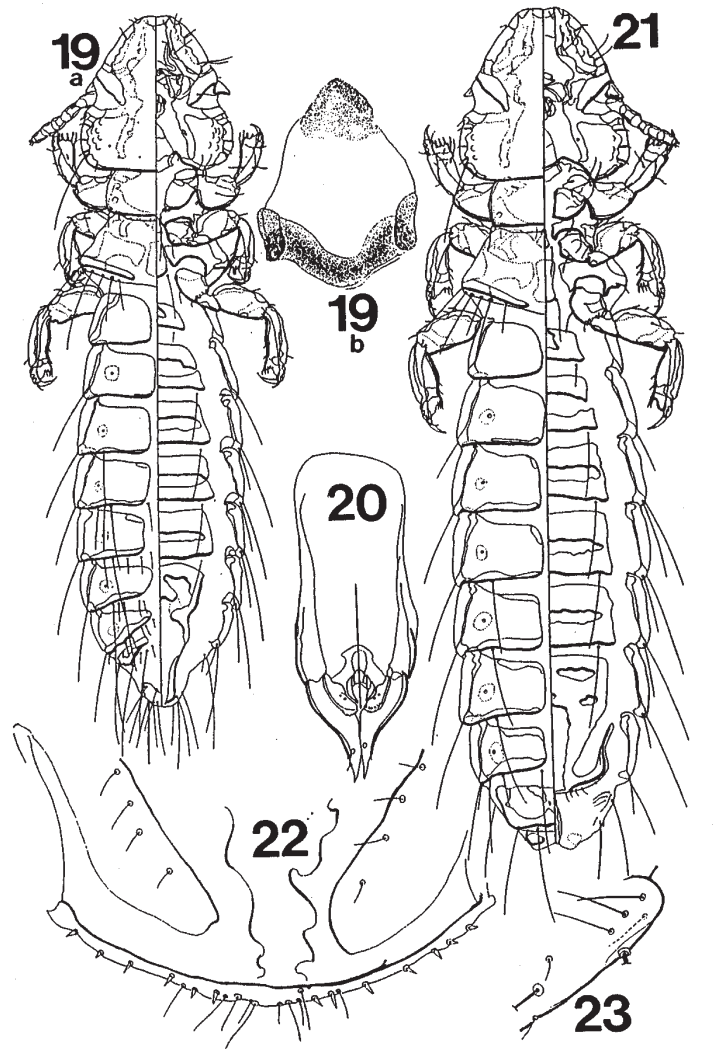

Figs. 19-23.- Brueelia solitaria Cicchino, 1988: 19a) macho, $19 \mathrm{~b}$ y 20) placa gular y genitalia masculinas, 21) hembra, 22 y 23 ) vulva y gonapófisis femeninas.

Figs. 19-23.- Brueelia solitaria Cicchino, 1988: 19a) male, $19 \mathrm{~b}$ and 20) male gular plate and genitalia, 21) female, 22 and 23) female vulva and gonapophysis.

Anchura temporal Longitud del protórax Anchura del protórax Longitud del pterotórax Anchura del pterotórax Longitud del abdomen Anchura del abdomen Longitud total

$\begin{array}{cc}0,360-0,371 & 0,397-0,405 \\ 0,120-0,127 & 0,127-0,142 \\ 0,210-0,217 & 0,232 \\ 0,176-0,187 & 0,195-0,202 \\ 0,349-0,360 & 0,379-0,472 \\ 1,057-1,110 & 1,140-1,365 \\ 0,457-0,510 & 0,510-0,547 \\ 1,643-1,757 & 1,851-2,078\end{array}$

HoSPEDADOR TIPO: Sturnella loyca loyca (Molina, 1782).

OBSERVACIONES: muy semejante a $B$. picturata y $B$. pseudopicturata, de las que se diferencia por la forma de la cabeza, mayor tamaño, detalles de la genitalia masculina, quetotaxia abdominal del macho, y por tener sólo una seta pleural en lugar de dos.

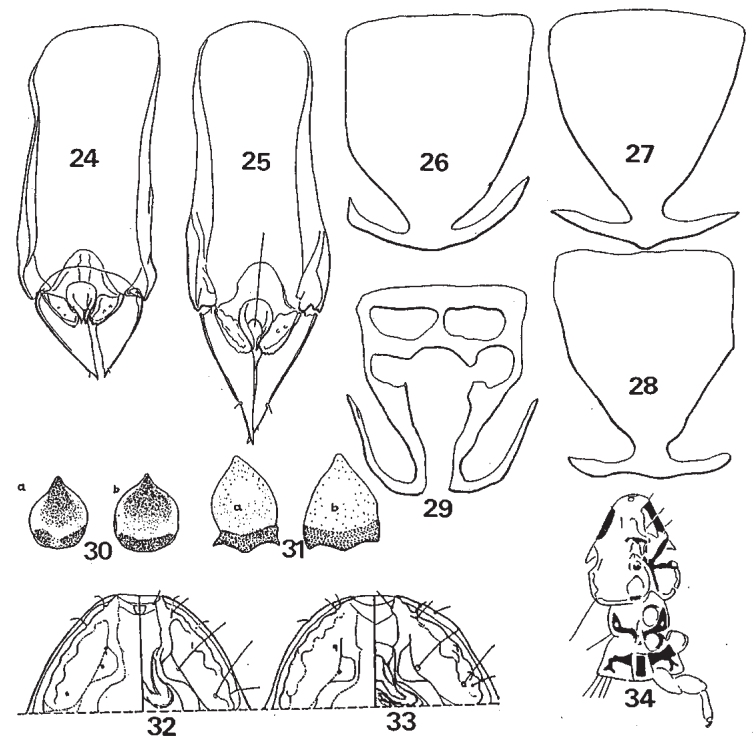

Figs. 24-34. - 24 y 25) genitalia masculina de Brueelia picturata (Osborn, 1896) y B. boae sp. n.; 26 a 29) placas subgenitales femeninas de 26) B. picturata, 27 y 28) B. boae, 29) $B$. decumana sp. n.; 30 y 31) placas gulares de B. picturata (a macho, b hembra) y $B$. boae (a macho, b hembra); 32 y 33) porción preantenal de B. pseudopicturata Cicchino, 1986 y $B$. picturata; 34) B. cela Stafford, 1943 (redibujado).

Figs. 24-34.- 24 and 25) male genitalia of Brueelia picturata (Osborn, 1896) and B. boae sp. n.; 26-29) female subgenital plates of 26) B. picturata, 27 and 28) B. boae, 29) B. decumana sp. n.; 30 and 31) gular plates of B. picturata (a male, b female) and $B$. boae (a male, b female); 32 and 33) preantennal portion of B. pseudopicturata Cicchino, 1986 and B. picturata; 34) B. cela Stafford, 1943 (redrawn).

\section{Brueelia abrupta (Osborn, 1896)}

Nirmus abruptus Osborn, 1896. Bull. U.S. Dept. Agric. (Bur. Entomol.) (n.s.), 5: 229, pl. II, Fig. 6.

Brüelia abrupta: Hopkins \& Clay, 1952. Checklist: 52; Emerson, 1960. Proc. Biol. Soc. Washington, 73: 160. Brueelia abrupta Emerson, 1972. Checklist, Part. I: 25.

HOSPEDADOR TIPO: Colinus virginianus (error), pero en la preparación $n^{0} 27338$ (307) del Museum of Comparative Zoology (USA) conteniendo una hembra (designada por Emerson, 1960, como Lectotipo) y una ninfa, figura "Perdix americana". Hopkins \& Clay (1952) hacen notar que su hospedador verdadero debe ser algún paseriforme de la subfamilia Icterinae, punto de vista también compartido por Emerson $(1960,1972)$.

Por nuestra parte adoptamos provisionalmente el criterio de estos autores, ante la imposibilidad de 

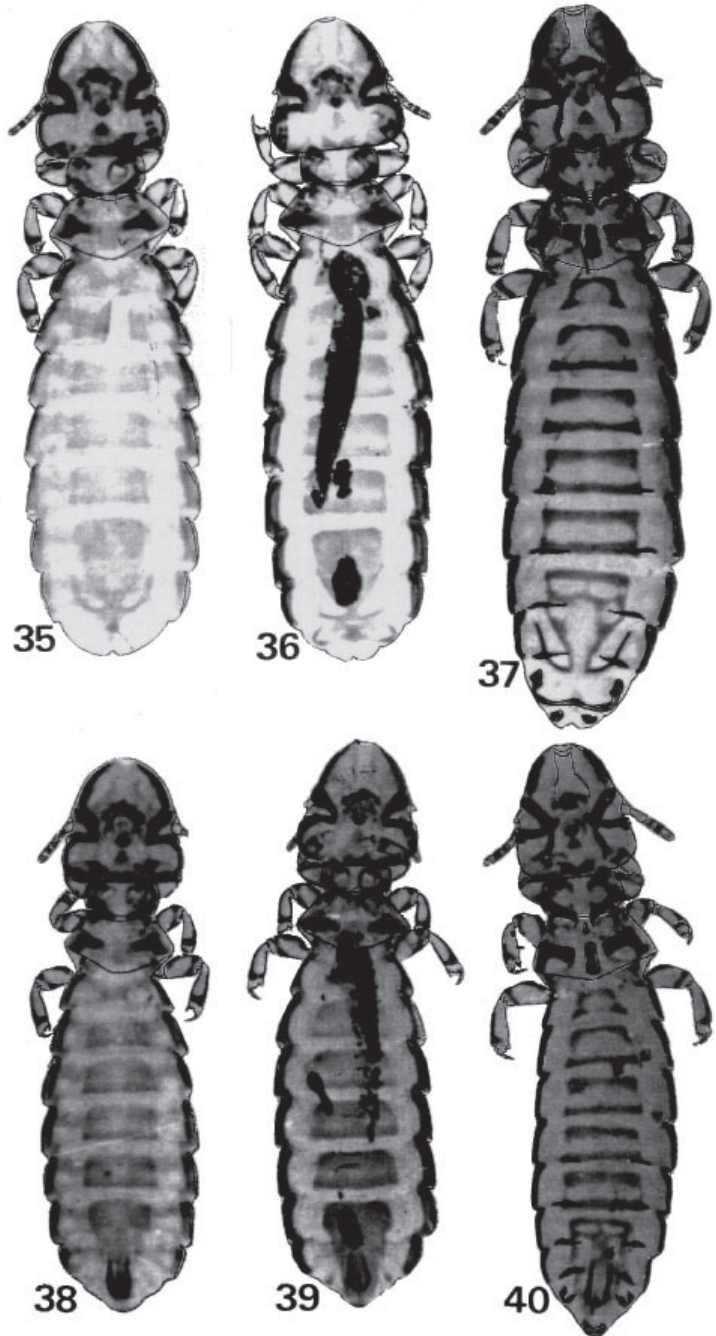

Figs. 35-40.- Habitus de Brueelia picturata (Osborn, 1896): 35) hembra y 38) macho; B. boae sp. n.: 36) hembra y 39) macho; $B$. decumana sp. n.: 37) hembra y 40) macho.

Figs. 35-40.- Habitus of Brueelia picturata (Osborn, 1896): 35) female and 38) male; B. boae sp. n.: 36) female and 39) male; $B$. decumana sp. n.: 37) female and 40) male.

examinar el lectotipo. De ser así, existen dificultades para atribuirla a alguno de los dos grandes grupos de especies que aquí proponemos, pero las características surgidas del examen de su descripción original y microfotografías parecen encuadrarla mejor dentro del grupo picturata por las siguientes razones:

a) El borde pulvinar de la sutura clipeolabral no tiene máculas. La misma característica se presenta en el subgrupo cela dentro del grupo ornatissima, pero este último es muy distinto por las demás características. b) Pleuritos anchamente pigmentados de parduzco. c) Ausencia de marginaciones pigmentadas, al menos en alguno de los terguitos.

d) Placa subgenital de la hembra sin fenestraciones.

e) Pigmentación de la carena marginal muy extendida hacia el disco cefálico.

De su descripción original se desprende que la quetotaxia paratergal es: II-III, 0; IV-VIII, 1, "and single hairs at the lateral angles on segments 3 to 7".

También proporciona las siguientes medidas:

$\begin{array}{ll}\text { Longitud de la cabeza } & 0,39 \\ \text { Anchura temporal } & 0,35 \\ \text { Longitud del abdomen } & 0,51 \\ \text { Longitud total } & 1,69\end{array}$

Entre el material de Estados Unidos y de Mexico, que se nos enviara para estudio, no hallamos ninguna Brueelia que presente las características atribuidas a B. abrupta.

Solamente el examen del lectotipo y colecciones más representativas de los Estados Unidos y México podrán definir cuál es el verdadero hospedador de esta especie.

\section{GRUPO ORNATISSIMA SUBGRUPO CELA}

Brueelia cela Stafford, 1943

(Fig. 34)

Brüelia cela Stafford, 1943. Bol. Entomol. Venezol., 2: 53, figs. 40-41.

Brüelia cela: Hopkins \& Clay, 1952. Checklist: 54 (como sinónimo de B. amazonae Stafford).

No examinamos materiales de esta especie; de cualquier modo, su descripción original y figuras son suficientemente claras para distinguirla de sus dos congéneres más próximas: $B$. virgata (Kellogg, 1899) y $B$. decumana sp. n. De ninguna manera podemos sostener la postura de Hopkings \& Clay (1952), quienes consideran que B. cela es un sinónimo de $B$. amazonae Stafford, 1943, ya que sus características particulares justifican la creación de un subgrupo peculiar dentro del grupo ornatissima: subgrupo cela, cuyas características hemos citado en el cuadro I, y que reune formas parásitas de Cacicus y géneros con él relacionados. Ver los comentarios pertinentes a $B$. amazonae.

MEDIDAS CORPORALES (proporcionadas por Stafford, 1943, para el holotipo macho):

$\begin{array}{ll}\text { Longitud de la cabeza } & 0,370 \\ \text { Anchura temporal } & 0,340 \\ \text { Longitud total } & 1,570\end{array}$

HoSPEDADOR TIPO: Cacicus cela cela (Linné, 1758). 


\section{Brueelia virgata (Kellogg, 1899)}

Nirmus virgatus Kellogg, 1899. Occas. Pap. California Acad. Sci., 6: 19, pl. 2, fig. 5.

Bizarrifrons virgata: Eichler, 1938. Zool. Anz., 124(9/10): 234235.

Brüelia virgata: Hopkins \& Clay, 1952. Checklist: 62.

No nos fue posible obtener materiales pertenecientes a esta especie. La descripción de Kellogg es bastante clara como para definir que esta especie debe ubicarse dentro del subgrupo cela, grupo ornatissima: "and does not possess the distinct bands internal to the antennal bands of the head of illustris". Fácilmente separable de B. cela Stafford, 1943, la especie más próxima, por la forma de la cabeza, tan larga como ancha, distinta distribución del pigmento en cabeza, terguitos y esternitos abdominales, y medidas de las distintas estructuras corporales.

MEDIDAS CORPORALES (proporcionadas por Kellogg, 1899):

Longitud de la cabeza

Anchura temporal

Anchura del abdomen

Longitud total

$\begin{array}{cc}\text { Macho } & \text { Hembra } \\ 0,43 & 0,41 \\ 0,43 & 0,43 \\ 0,47 & 0,53 \\ 1,28 & 1,50\end{array}$

HOSPEDADOR TIPO: Amblycercus holosericeus holosericeus (Lichtenstein, 1830).

\section{Brueelia solitaria Cicchino, 1986} (Figs. 19 a 23)

Brueelia solitaria Cicchino, 1986. Spheniscus, 8: 23-26, figs. 7-12.

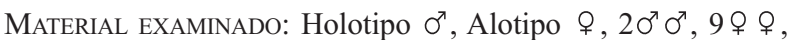
1 i inmadura y 4 ninfas III, Paratipos, Bella Vista, Corrientes, Argentina, 3-V-1980 (MLP).

\section{REDESCRIPCIÓN:}

Macho: Aspecto general como en la figura 19a. Cabeza más larga que ancha. Borde preantenal apenas convexo. Carena marginal muy espesada, internamente sinuosa y pigmentada en $4 / 5$ partes de su longitud, ampliándose su pigmentación algo hacia el disco cefálico. Borde pulvinar de la sutura frontoclipeal con una mácula algo difusa ocupando menos de la mitad de su longitud. Área nodal de la sutura frontoclipeal muy espesada y oscurecida, aclarándose hacia la zona genal. Área subgenal y suturas hipostomal, occipital y postoccipital anchamente pigmentadas. Distribución del pigmento de la placa gular indicado en la figura 19b. Carenas temporales

sumamente desarrolladas y pigmentadas, extendiéndose algo su pigmentación hacia la zona de inserción de los aductores mandibulares, cuyas improntas son visibles en número de seis o más. Apodemas pro y pterotorácicos bien desarrollados y pigmentados. Borde posterior del pterotórax marginado en sus $2 / 3$ de pardo. Terguito II incoloro, III apenas marginado posteriormente, IV-VIII marginados posteriormente y V-VI también marginados en su ángulo antero-interno, IX con el aspecto visible en la figura 19a. Paraterguitos muy desarrollados y fuertemente pigmentados. Esternitos II-VI fenestrados, y contactando poco sus áreas pigmentadas anterior y posterior. Placa subgenital con una gran fenestra posterocentral con la que coalescen una fenestra irregular ubicada en la zona antero-externa a cada lado de la placa. Quetotaxia tergal: setas postespiraculares largas presentes en IV-VII, 1-3 setas postespiraculares accesorias medianas en V-VII, dos setas tergales posteriores pequeñas en VI-VII, setas suturales pequeñas en V-VII. Quetotaxia paratergal: II, 0; III, 1; IV-VII, 2. Setas esternales posteriores: II, pequeña; III-VI, medianas a largas. Genitalia (Fig. 20): placa basal larga, de bordes laterales cóncavos; parámeros pigmentados, largos; escleritos laterales del complejo endomeral con una hilera posterior de seis a ocho mamelones, y una hilera ventral paralela a la anterior de alrededor de seis.

Hembra: como en la figura 21. Aspecto general semejante al macho, difiriendo en tamaño, medidas corporales, quetotaxia abdominal y terminalia. Quetotaxia paratergal igual a la del macho. Placa subgenital con una fenestra central alargada y dos fenestras superiores a cada lado, de las que la inferior es más pequeña, y que no coalescen con la central. Setas esternales III-IV largas. Setas postespiraculares largas en V-VII. Terguito $\mathrm{X}+\mathrm{XI}$ con una mácula notable a cada lado. Gonapófisis (Fig. 23) normalmente con tres setas, pudiendo aparecer incospicuamente una cuarta de similares características. Vulva (Fig. 22) con 6-7 setas cortas espiniformes y cinco delgadas a cada lado. Placa subgenital conspicuamente con $4+4$ setas.

\section{MEDIDAS CORPORALES:}

Longitud de la cabeza

Anchura preantenal

Anchura temporal

Longitud del protórax

Anchura del protórax

Longitud del pterotórax

Anchura del pterotórax

Longitud del abdomen

Anchura del abdomen

Longitud total

$\begin{array}{cc}\text { Machos } & \text { Hembras } \\ 0,355 & 0,341-0,382 \\ 0,261-0,265 & 0,261-0,295 \\ 0,301-0,315 & 0,321-0,361 \\ 0,124-0,131 & 0,134-0,151 \\ 0,201-0,215 & 0,214-0,231 \\ 0,151-0,161 & 0,161-0,185 \\ 0,291-0,305 & 0,305-0,345 \\ 0,843-0,904 & 1,018-1,155 \\ 0,341-0,375 & 0,396-0,442 \\ 1,446-1,506 & 1,606-1,811\end{array}$


HOSPEDADOR TIPO: Cacicus solitarius (Vieillot, 1816).

OBSERVACIONES: especie muy semejante a $B$. cela Stafford, 1943, de la que difiere sobre todo por sus dimensiones y distribución del pigmento. La quetotaxia de ambas especies no ha podido ser confrontada por carecer de ejemplares de $B$. cela para su estudio,ya que no está consignada en su descripción original.

Brueelia decumana $\mathrm{sp} . \mathrm{n}$.

(Figs. 14 a 18, 29, 37 y 40)

Material eXAminado: Holotipo $0^{x}$, Alotipo $\&$ y $160^{x} 0^{x}$ y 15 우, Paratipos, y 11 ninfas, ex Psarocolius decumanus maculosus (Chapman), Manantiales, prov. Corrientes, Argentina (ACC y KCE); $10^{\pi}$ y 1 오․ Paratipos, (ACC) ex Scaphidura $o$. oryzivora (Gmelin), Ituzaingó, prov. Corrientes, Argentina, 14VII-19 (ACC, KCE, MMNH y MLP).

\section{DESCRIPCIÓN:}

Macho: aspecto general como en la figura 14. Cabeza suboval, mucho más larga que ancha. Borde preantenal muy ancho, con márgenes ligeramente convexos. Carena marginal muy desarrollada, internamente sinuosa y fuertemente pigmentada en 3/4 de su longitud; su pigmentación, en una tonalidad mucho más clara, se extiende hasta la inserción de los músculos cibariales, poco visibles, en número de 3-4. Borde pulvinar de la sutura frontoclipeal desprovisto de mácula. Placa gular semejante a $B$. solitaria. Área nodal de la sutura frontoclipeal muy oscura, aclarándose algo hacia la zona genal. Carena temporal despigmentada. Área subgenal y suturas hipostomal, occipital y postoccipital angostamente pigmentadas. Apodemas pro y pterotorácicos de desarrollo normal. Placa prosternal pequeña, ovoide, la metasternal, moderada, de bordes laterales poco cóncavos. Borde posterior del pterotórax desprovisto de marginación. Terguitos II-IV sin marginaciones; V-VIII solo marginados en su borde posterior. Quetotaxia tergal: seta postespiracular larga en VVII; una seta postespiracular accesoria mediana en VI-VII; dos setas tergales posteriores en VI-VII y una sutural pequeña en V-VIII. Paraterguitos bien pigmentados, relativamente angostos; su quetotaxia es: II, 0; III, 0-1; IV, 1-2; V-VIII, 2. Esternitos II-VI fenestrados; el II casi ha perdido el pigmento de su porción anterior no en contacto; VI con fenestra transversa, y en contacto. Placa subgenital con una amplísima fenestra central por coalescencia de las dos fenestras laterales inferiores a ella, y presencia de dos fenestras superiores medianas y transversas.
Genitalia: parámeros pigmentados, escleritos laterales del complejo endomeral terminado en una hilera de 5-6 tubérculos pequeños, habiendo varias series cortas de ellos en su cara inferior (Fig. 15); longitud máxima 0,204-0,215, anchura máxima 0,064-0,075.

Hembra: como en la figura 16. Aspecto general similar al del macho, difiriendo en tamaño, medidas, terminalia y quetotaxia abdominal. Quetotaxia paratergal como en el macho. Vulva: con 5-6 setas espiniformes y 0 -1 delgadas a cada lado, hilera inferior normalmente con cuatro setas delgadas (Fig. 18). Gonapófisis (Fig. 17) con dos setas. Placa subgenital (Fig. 29) característica, con una fenestra central que llega al borde posterior y con la que coalescen las dos fenestras laterales inferiores, y dos fenestras laterales superiores medianas. Terguitos $\mathrm{X}+\mathrm{XI}$ con una mácula a cada lado.

\section{MEDIDAS CORPORALES:}

$\begin{array}{lcc} & \text { Machos } & \text { Hembras } \\ \text { Longitud de la cabeza } & 0,484-0,516 & 0,495-0,538 \\ \text { Anchura preantenal } & 0,325-0,357 & 0,344-0,376 \\ \text { Anchura temporal } & 0,387-0,430 & 0,452-0,463 \\ \text { Longitud del protórax } & 0,150-0,172 & 0,150-0,193 \\ \text { Anchura del protórax } & 0,290-0,312 & 0,312-0,323 \\ \text { Longitud del pterotórax } & 0,204-0,258 & 0,215-0,280 \\ \text { Anchura del pterotórax } & 0,441-0,463 & 0,452-0,484 \\ \text { Longitud del abdomen } & 1,195-1,313 & 1,378-1,647 \\ \text { Anchura del abdomen } & 0,527-0,560 & 0,538-0,624 \\ \text { Longitud total } & 2,035-2,154 & 2,207-2,552\end{array}$

HosPeDADOR TIPO: Psarocolius decumanus maculosus (Chapman, 1920).

HoSPEDADOR OCASIONAL: Scaphidura oryzivora oryzivora (Gmelin, 1788).

OBSERVACIONES: especie del subgrupo cela, grupo ornatissima, muy característica por su gran tamaño y silueta, difiriendo en esto y demás aspectos cromáticos y merísticos de las otras especies de este subgrupo. El hallazgo de una serie de individuos en Scaphidura o. oryzivora (Gmelin) puede interpretarse como una colonización secundaria a partir de Psarocolius, además ambos hospedadores provienen de la misma localidad: Manantiales, Corrientes, Argentina.

\section{SUBGRUPO AMAZONAE}

Brueelia ornatissima (Giebel, 1874)

(Figs. 41 a 44, 100, 101, 106, 118 y 119)

Nirmus ornatissimus Giebel, 1874. Insecta Epizoica: 144-145; Piaget, 1880. Les Pédiculines: 163; Osborn, 1896. Bull. U.S. Dep. Agric. (Bur. Entomol.) (n.s.), 5: 524. 


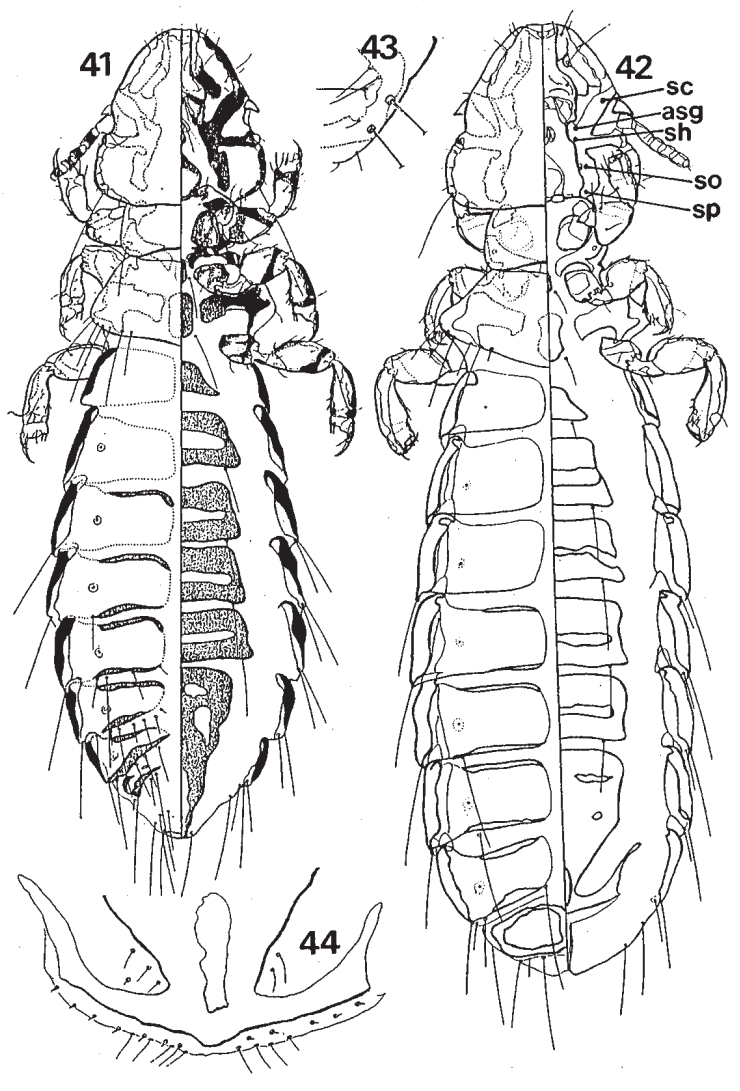

Figs. 41-44.- Brueelia ornatissima: 41) macho, 42) hembra, 43) gonapófisis, 44) vulva. Abreviaturas: asg: área subgenal; sc: sutura clipeofrontal; sh: sutura hipostomal; so: sutura occipital; sp: sutura postoccipital.

Figs. 41-44.- Brueelia ornatissima: 41) male, 42) female, 43) gonapophysis, 44) vulva. Abbreviations: asg: subgenal area; sc: clypeofrontal suture; $\mathbf{s h}$ : hypostomal suture; so: occipital suture; sp: postoccipital suture.

Nirmus illustris Kellogg, 1896. Proc. California Acad. Sci., (2)6: 494, pl. LXVII, fig. 4.

Degeeriella illustris: Geist, 1935. Ohio J. Sci., 31(6): 509.

Bizarrifrons illustris: Eichler, 1938. Zool. Anz., 124(9/10): 230-231.

Bizarrifrons ornatissima: Eichler, 1938. Zool. Anz., 124(9/10): 223.

Brüelia illustris: Hopkins \& Clay, 1952. Checklist: 56 (como sinónimo de Brueelia ornatissima); Carriker, 1957. Microentomology, 22(5): 100.

Brüelia ornatissima: Hopkins \& Clay, 1952. Checklist: 59; Stafford, 1943. Bol. Entomol. Venezol., 2(1): 54.

Brueelia ornatissima: Emerson, 1972. Checklist, Pt. I: 31; Pt. IV: 207.

Material EXAMINADO: $30^{\circ}, 1$ \% y 7 ninfas ex Quiscalus quiscula, Linn County, Kansas, USA, 11-IX-1949 (NMNH); 1 ninfa, mismo hospedador, Baltimore, Maryland, USA, 1935 (KCE y MLP); $20^{x} 0^{x}, 1 \%$ y 1 ninfa ex Tangavius aeneus, Halifax, North Carolina, USA, 3-XII-1936; 1 ninfa, mismo hos- pedador, Ft. Dupont, Delaware, USA, 13-IV-1993; $40^{7} 0^{7}$ y 6 $\sigma^{x} \sigma^{x}$, mismo hospedador, Laurel Maryland, USA, 1935 (KCE y MLP).

\section{REDESCRIPCIÓN:}

Macho: aspecto general como en la figura 41, característico, robusto. Cabeza suboval, más larga que ancha. Borde preantenal convexo. Carena marginal espesada, internamente ondulada y fuertemente pigmentada en casi toda su extensión. No se observan con claridad las huellas de inserción de los músculos cibariales. Borde pulvinar de la sutura frontoclipeal con una mácula que ocupa aproximadamente la mitad de su longitud. Área nodal de la sutura frontoclipeal fuertemente oscurecida, aclarándose apenas hacia la zona genal. Área subgenal y suturas hipostomal, occipital y postoccipital anchamente pigmentadas. Placa gular característica, como en la figura 41. Carenas temporales fuertemente pigmentadas en toda su extensión. Apodemas protorácicos moderadamente desarrollados, metatorácicos muy desarrollados y pigmentados. Placa mesosternal desarrollada, y metasternal grande, subrectangular y de vértices redondeados. Pterotórax sin marginación pigmentada en su borde posterior. Terguitos II-III despigmentados; IV marginado anteriormente; V-IX marginados en sus bordes anterior y posterior. Terguito $\mathrm{V}$ con una seta postespiracular mediana; VI-VII con una postespiracular larga y una accesoria mediana a cada lado; VI con una y VII con tres setas tergales posteriores pequeñas. Setas suturales pequeñas, presentes en VI-VIII. Quetotaxia paratergal: II, 0; III, 0-1; IVVIII, 2. Paraterguitos muy pigmentados, negruzcuos. Esternitos: II no fenestrado, algo más claro en su centro; III-VI con fenestra reducida, muy angosta. Placa subgenital con una fenestra medial desplazada posteriormente y de regular extensión, y dos pequeñas fenestras laterales a cada lado, de las que la superior es mas transversa. Genitalia (Fig. 106): placa basal relativamente ancha y desarrollada; parámeros pigmentados, escleritos laterales del complejo endomeral con su borde posterior con dos hileras de 6-8 tubérculos de regular tamaño; longitud máxima 0,147-0,181, anchura máxima 0,0630,081 .

Hembra: como en la figura 42. Aspecto general semejante al del macho, difiriendo en tamaño, medidas, terminalia y quetotaxia tergal. Placa subgenital (Figs. 100 y 101) con una fenestra posterior reducida y poco definida (a veces casi falta, estando indicada por un área más clara), y dos fenestras laterales a cada lado, irregulares y de poca extensión. Vulva (Fig. 44) con 5-6 setas espiniformes y 


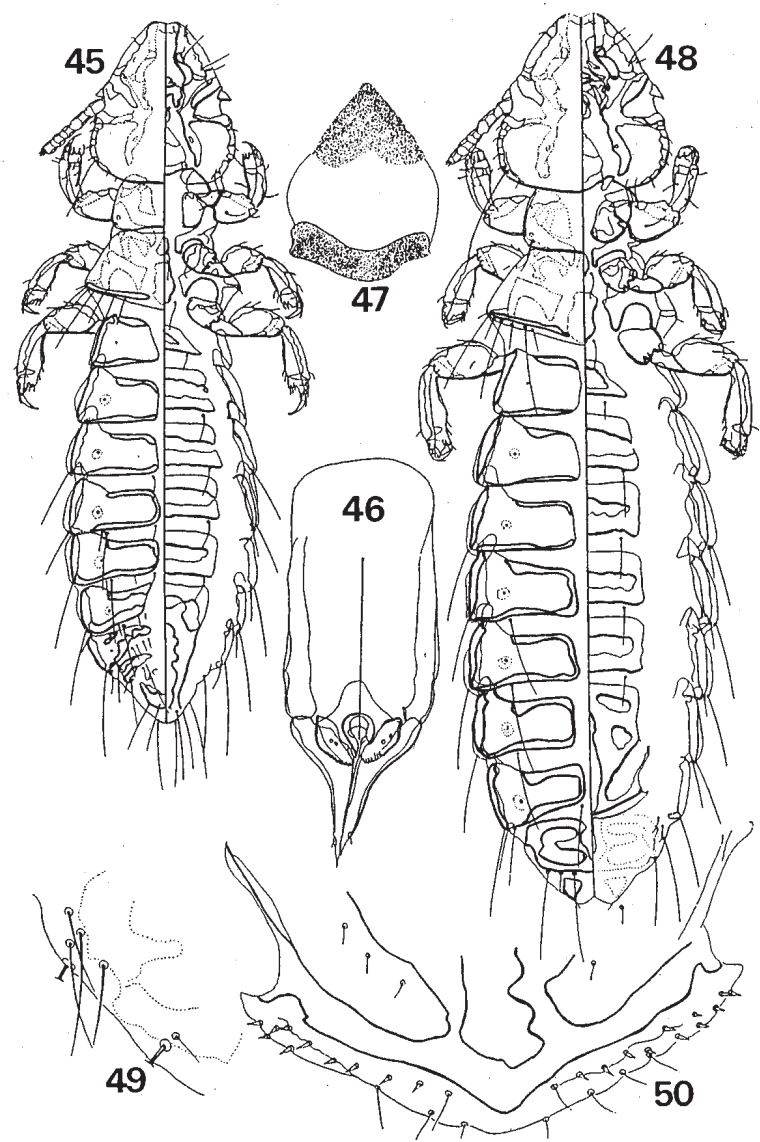

Figs. 45-50.- Brueelia ruficapilla: 45) macho, 46) genitalia del macho, 47) placa gular del macho, 48) hembra, 49) gonapófisis, 50) vulva.

Figs. 45-50.- Brueelia ruficapilla: 45) male, 46) male genitalia, 47) male gular plate, 48) female, 49) gonapophysis, 50) vulva.

una delgada pequeña a cada lado, y 4-5 pequeñas y delgadas en una hilera inferior. Gonapófisis con tres setas (Fig. 43).

MEDIDAS CORPORALES:

$\begin{array}{lcc} & \text { Machos } & \text { Hembras } \\ \text { Longitud de la cabeza } & 0,330-0,364 & 0,367-0,393 \\ \text { Anchura preantenal } & 0,270-0,295 & 0,300-0,326 \\ \text { Anchura temporal } & 0,333-0,375 & 0,371-0,420 \\ \text { Longitud del protórax } & 0,131-0,157 & 0,135-0,172 \\ \text { Anchura del protórax } & 0,221-0,225 & 0,232-0,285 \\ \text { Longitud del pterotórax } & 0,172-0,187 & 0,195-0,217 \\ \text { Anchura del pterotórax } & 0,345-0,409 & 0,367-0,457 \\ \text { Longitud del abdomen } & 0,907-1,102 & 1,012-1,237 \\ \text { Anchura del abdomen } & 0,457-0,532 & 0,487-0,637 \\ \text { Longitud total } & 1,521-1,662 & 1,687-1,983\end{array}$

HOSPEDADOR TIPO: Agelaius phoeniceus phoeniceus (Linné, 1766).

OtROS HOSPEDADORES: Quiscalus quiscula (Linné, 1758), Tangavius aeneus aeneus (Wagler, 1829) y Dolichonyx oryzivorus (Linné, 1758).

OBSERVACIONES: esta especie tan característica y repetidamente citada sobre su hospedador tipo, presenta una distribución en otros hospedadores que aún no está del todo clara. Ya Geist (1935) la citó de Quiscalus quiscula aeneus en Lancaster, USA y Dolichonyx oryzivorus en Columbus, USA. El material estudiado indica que al presente es la única especie del género hallada en Quiscalus quiscula por lo menos en Kansas y Maryland, USA, donde parece ya haberse establecido definitivamente en ese hospedador. No vimos material del segundo hospedador citado. Además, examinamos dos colecciones sobre Tangavius aeneus aeneus (Wagler) de Halifax, North Carolina y Delaware (Ft. Dupont), ambas en USA, con los mismos resultados, pero con materiales de este mismo hospedador de Virginia y Michigan, USA, identificamos una nueva especie, B. mauroi. Este último hecho puede también tener una explicación en los hábitos parasitarios de incubación de Tangavius en distintos Icterinae, no obstante que Agelaius phoeniceus, hospedador tipo de $B$. ornatissima, sea realmente poco parasitado por esta ave (dato tomado de Friedman, 1963). Además, en materiales de Tangavius hallamos desertores de Sturnella magna - B. picturata (Osborn, 1896), dos hembras - y de Sturnus vulgaris - B. nebulosa (Burmeister, 1838), una hembra-, ninguno de los cuales figura en la lista de hospedadores parasitados por Tangavius proporcionada por Friedman (1963).

Por todo lo expuesto existe la posibilidad que $B$. ornatissima se distribuya primariamente sobre determinados hospedadores Ictéridos por razones de índole geográfica y sólo secundariamente por selección de hospedadores.

Brueelia ruficapilla Cicchino, 1990 (Figs. 45 a 50)

Brueelia ruficapilla Cicchino, 1990. Spheniscus, 8: 22

Material examinado: $30^{7} \sigma^{\pi}$ y 5 \% , Embalse, Córdoba, Argentina, V-1981 (MLP).

REDESCRIPCIÓN:

Macho: Aspecto general como en la figura 45. Cabeza oval, más larga que ancha. Borde preantenal apenas convexo; carena marginal espesa, internamente sinuosa y pigmentada en sus $4 / 5$ partes. Improntas de inserción de los músculos cibariales 
visibles en escaso número. Borde pulvinar de la sutura frontoclipeal con una mácula ocupando algo menos de la mitad de su longitud. Área nodal de la sutura frontoclipeal fuertemente oscurecida, aclarándose hacia la zona genal. Área subgenal y suturas hipostomal y postoccipital anchamente pigmentadas. Placa gular con la pigmentacion distribuida según la figura 47. Carenas temporales bien desarrolladas y pigmentadas en toda su longitud, excepto un pequeño tramo comprendido entre las setas temporales 1 y 2 . Apodemas pro y pterotorácicos bien desarrollados y pigmentados. Borde posterior del pterotórax angostamente marginado de pardo. terguitos II-IX marginados anterior y posteriormente de parduzco. Paraterguitos fuertemente pigmentados. Quetotaxia paratergal: II-III, 0; IV-VII, 2. Todos los esternitos fenestrados, III-V con sus áreas pigmentadas anterior y posterior apenas contactando lateralmente, o a veces sin contacto alguno. Placa subgenital con una fenestra lateral amplia a cada lado y una enorme fenestra medial alargada. Quetotaxia tergal: suturales pequeñas en IV-VII, postespiracular larga y accesoria mediana en V-VII. Una seta tergal posterior pequeña en VI-VII, tres en VIII. Genitalia (Fig. 40): placa basal ancha, de bordes laterales subparalelos; parámeros pigmentados, largos; escleritos laterales del complejo endomeral con su borde posterior provisto de 7-8 mamelones.

Hembra: Como en la figura 48. Aspecto general semejante al macho, difiriendo en tamaño, medidas corporales, terminalia y quetotaxia tergal. Quetotaxia paratergal igual a la del macho. Placa subgenital con dos fenestras a cada lado, y una medial estrecha y muy alargada. Vulva (Fig. 50) con 10 u 11 setas espiniformes y 4-5 delgadas y más largas a cada lado. Gonapófisis (Fig. 49) normalmente con cuatro setas. Terguito X+XI con una amplia mácula subtriangular parduzca a cada lado.

MEDIDAS CORPORALES:

$\begin{array}{lcc} & \text { Machos } & \text { Hembras } \\ \text { Longitud de la cabeza } & 0,261-0,271 & 0,271-0,301 \\ \text { Anchura preantenal } & 0,205-0,211 & 0,205-0,241 \\ \text { Anchura temporal } & 0,241-0,250 & 0,251-0,281 \\ \text { Longitud del protórax } & 0,104-0,120 & 0,120-0,141 \\ \text { Anchura del protórax } & 0,171-0,181 & 0,175-0,201 \\ \text { Longitud del pterotórax } & 0,104-0,131 & 0,141-0,161 \\ \text { Anchura del pterotórax } & 0,250-0,271 & 0,271-0,301 \\ \text { Longitud del abdomen } & 0,683-0,763 & 0,843-0,934 \\ \text { Anchura del abdomen } & 0,321-0,341 & 0,371-0,412 \\ \text { Longitud total } & 1,175-1,274 & 1,360-1,496\end{array}$

HOSPEDADOR TIPO: Agelaius ruficapillus ruficapillus Vieillot, 1819.
Brueelia mirabile Carriker, 1963

(Figs. 51, 52, 102 y 126)

Brüelia mirabile Carriker, 1963. Rev. Bras. Biol., 23(3): 306307.

Material EXAMinado: $10^{7}$ y 1 ninfa sobre su hospedador tipo, Mato Grosso, Brasil, IX-1892 (MLP).

Solamente nos fue posible examinar un macho procedente de su hospedador tipo, por lo que lo redescribimos aquí; los caracteres de la hembra están todos tomados de la ilustración de Carriker (1963), ya que su descripción original no tiene, salvo las medidas, datos de valor diagnóstico.

REDESCRIPCIÓN DEL MACHO: aspecto general como en la figura 52. Cabeza suboval. Borde preantenal convexo. Carena marginal espesa, ondulada en su borde interno y pigmentada en $2 / 3$ de su longitud. No se observan con claridad la inserción de los musculos cibariales. Borde pulvinar de la sutura frontoclipeal con una mácula que ocupa $1 / 2$ de su longitud, y que no llega a su borde interno. Área nodal de la sutura frontoclipeal muy oscurecida, aclarándose algo hacia la zona genal. Área subgenal y suturas hipostomal, occipital y postoccipital anchamente pigmentadas. Carena temporal pigmentada. Apodemas pro y pterotorácicos moderadamente desarrollados y pigmentados. Pterotórax marginado en su borde posterior. Placa mesosternal bien desarrollada, algo alargada; metasternal grande, subrectangular. Terguitos II-VII marginados en sus bordes anterior y posterior; VIII y IX sólo en su borde posterior; $\mathrm{X}$ indicado por una mácula más o menos redondeada. Terguitos V-VII con una seta postespiracular larga y una accesoria mediana; tambien puede existir una postespiracular mediana en IV. Setas suturales pequeñas en VVII; VI-VII con 3-4 setas tergales posteriores pequeñas. Quetotaxia paratergal: II-III, 0; IV-VII, 2. Esternitos II-VI con sus porciones anterior y posterior separadas o débilmente unidas por sus bordes, todos ellos muy transversos. Placa subgenital con una enorme fenestra central, que se trilobula hacia el extremo anterior, desdibujándose su extremo caudal. Genitalia (Fig. 102): placa basal corta y ancha, algo cóncava lateralmente; parámeros muy largos y delgados, pigmentados; escleritos laterales del complejo endomeral amplio, con su borde posterior con una hilera de pequeños denticulos, longitud máxima 0,258 , anchura máxima 0,096. La ilustración proporcionada por Carriker (1963, fig. 20) muestra parámeros pequeños, lo que no es real y seguramente se debe a una interpretacion deficiente de estas estructuras, probable- 


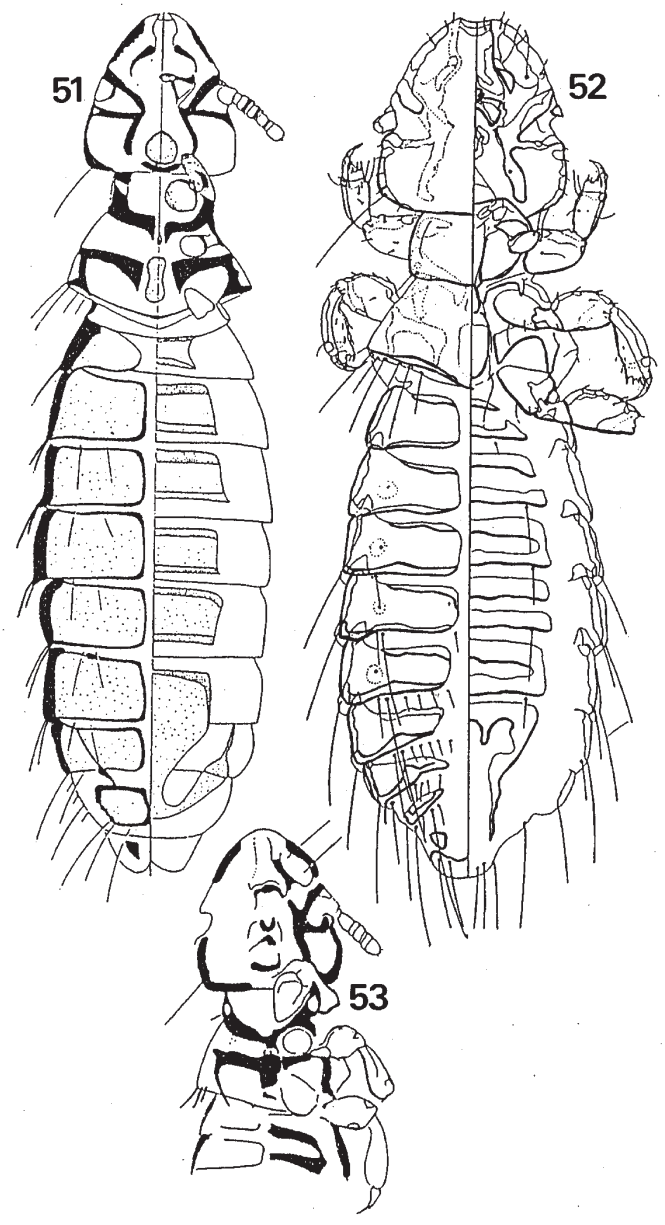

Figs. 51-53.- 51) Brueelia mirabile, hembra (de Carriker, 1963), 52) B. mirabile, macho, 53) B. amazonae, hembra (de Stafford, 1943).

Figs. 51-53. - 51) Brueelia mirabile, female (from Carriker, 1963), 52) B. mirabile, male, 53) B. amazonae, female (from Stafford, 1943).

mente debido a que se hallan en ese ejemplar vueltos hacia arriba formando un ángulo de $90^{\circ}$ con el plano del cuerpo.

MEDIDAS CORPORALES:

a) ejemplar de Mato Grosso, Brasil

$\begin{array}{ll}\text { Longitud de la cabeza } & 0,452 \\ \text { Anchura preantenal } & 0,323 \\ \text { Anchura temporal } & 0,370 \\ \text { Longitud del protórax } & 0,150 \\ \text { Anchura del protórax } & 0,259 \\ \text { Longitud del pterotórax } & 0,220 \\ \text { Anchura del pterotórax } & 0,441 \\ \text { Longitud del abdomen } & 1,077\end{array}$

Anchura del abdomen $\quad 0,549$

Longitud total $\quad 1,830$

b) proporcionadas por Carriker (1963)

$\begin{array}{lr}\text { Longitud de lacabeza } & 0,326 \\ \text { Anchura temporal } & 0,290 \\ \text { Longitud del protórax } & 0,130 \\ \text { Anchura del protórax } & 0,220 \\ \text { Longitud del pterotórax } & 0,160 \\ \text { Anchura del pterotórax } & 0,326 \\ \text { Longitud del abdomen } & 0,800 \\ \text { Anchura del abdomen } & 0,410 \\ \text { Longitud total } & 1,340\end{array}$

Hembra (Fig. 51) (según Carriker, 1963): caracteres generales semejantes a los del macho; terguitos II-VIII totalmente marginados; $\mathrm{X}+\mathrm{XI}$ con una mácula a cada lado. La quetotaxia tergal indicada, seguramente es errónea, debiendo ser en parte esternal (no se conoce ninguna especie de Brueelia parásita de Icteridae que tenga postespiraculares en III, ni setas postespiraculares accesorias en V-VII). Esternitos semejantes a los del macho. Placa subgenital con una enorme fenestra central.

MEDIDAS CORPORALES (proporcionadas por Carriker, 1963):

$\begin{array}{ll}\text { Longitud de la cabeza } & 0,320 \\ \text { Anchura temporal } & 0,345 \\ \text { Longitud del protórax } & 0,130 \\ \text { Anchura del protórax } & 0,250 \\ \text { Longitud del pterotórax } & 0,185 \\ \text { Anchura del pterotórax } & 0,380 \\ \text { Longitud del abdomen } & 1,080 \\ \text { Anchura del abdomen } & 0,460 \\ \text { Longitud total } & 1,690\end{array}$

HOSPEDADOR TIPO: Scaphidura oryzivora oryzivora (Gmelin, 1788).

OBSERVACIONES: La porción preantenal de la hembra ilustrada por Carriker aparece mucho más recta y convergente que la del macho examinado por nosotros, hecho debido a un artificio de preparacion, consistente en una contracción debida a una deshidratación enérgica, hecho muy corriente en otros ejemplares que tenemos en estudio y que han sido preparadas por aquel autor. Lo mismo puede comprobarse a nivel de los paraterguitos.

No vemos ninguna característica que podamos considerar definitoria para separar B. mirabile de $B$. amazonae Stafford, 1943 (cuyo verdadero hospedador permanece desconocido), siendo hasta las medidas prácticamente iguales. De modo que si $B$. mirabile es realmente diastinta de $B$. amazonae, sus diferencias son mínimas, y necesitan ser expuestas con sumo detalle. 
Brueelia amazonae Stafford, 1943

(Fig. 53)

Brüelia amazonae Stafford, 1943. Bol. Entomol. Venezol., 2(1): 52-53.

Brüelia amazonae: Hopkins \& Clay, 1952. Checklist: 53.

No obtuvimos materiales atribuibles a esta especie. De los caracteres aportados por Stafford (1943) surge que se trata de una especie muy afín con $B$. mirabile Carriker, 1963, tanto en sus caracteres morfológicos como cromáticos.

Evidentemente su hospedador tipo no es el Psitácido Amazona ochrocephala, tal como lo señalaron Hopkins \& Clay (1952).

Pero nos vemos forzados a disentir con los mencionados autores en un doble aspecto: primero, que $B$. cela Stafford, 1943 de ninguna manera puede sinonimizarse con B. amazonae, siendo muy distinta en sus características morfológicas y cromáticas; segundo, que Cacicus cela cela (L., 1758) no puede ser el hospedador tipo de $B$. amazonae, ya que el grupo de especies parásitas de Cacicus y géneros relacionados tienen como característica visible la ausencia de mácula fuertemente pigmentada en el borde pulvinar de la sutura frontoclipeal, y que sî posee B. amazonae; por ello, concluimos que su verdadero hospedador nos parece aún desconocido.

MEDIDAS CORPORALES (proporcionadas por Stafford, 1943, para un macho):

Longitud de la cabeza $\quad 0,33$

Anchura temporal $\quad 0,30$

Longitud total $\quad 1,35$

\section{Brueelia sallei Carriker, 1963}

(Fig. 81)

Brueelia sallei Carriker, 1963. Rev. Bras. Biol., 23(3): 307

No examinamos materiales referibles a esta especie, pero tanto la figura del macho, que reproducimos, como su diagnosis original, la separan de las demás especies estudiadas. La ilustración de su genitalia (solamente se conoce el macho), muy esquemática, no nos ofrece buenos caracteres diferenciales.

MEDIDAS (proporcionadas por Carriker, 1963):

$\begin{array}{ll}\text { Longitud de la cabeza } & 0,315 \\ \text { Anchura temporal } & 0,303 \\ \text { Longitud del protórax } & 0,160 \\ \text { Anchura del protórax } & 0,200 \\ \text { Longitud del pterotórax } & 0,140 \\ \text { Anchura del pterotórax } & 0,314 \\ \text { Longitud del abdomen } & 0,716\end{array}$

Anchura del abdomen $\quad 0,586$

Longitud total $\quad 1,250$

Hembra: desconocida.

HOSPEDADOR TIPO: Icterus nigrogularis nigrogularis (Hahn, 1819).

\section{Brueelia xanthocephali (Osborn, 1896)}

Nirmus xanthocephali Osborn, 1896. Bull. U.S. Dept. Agric., Bur. Entomol. (n.s.), 5: 224.

Brüelia xanthocephali: Eichler, 1938. Zool. Anz., 124(9/10): 235; Hopkins \& Clay, 1952. Checklist: 63; Emerson, 1960. Proc. Biol. Soc. Washington, 73: 161.

Brueelia xanthocephali: Emerson, 1972. Cheklist, Pt. I: 34; Pt IV: 207.

Según Emerson (1960) los tipos de esta especie no han podido ser localizados. Su descripción original, muy breve y desprovista de ilustraciones, tiene pocos caracteres valiosos que permitan separarla de B. ornatissima: "in the male the ventral median patch is extended to the tip from the sixth segment, there being clear lateral spaces on segment 6 , and a large clear median space on segments 7 and 8 , and lines of dusky running from this patch to margin of segment posteriorly on 6 and 7 and a small spots on 8 at sides. On yelowheaded blackbird (Xanthocephalus xanthocephalus), collected at Fairfax, Iowa (H.O. Collection)". Sugiere que la placa subgenital presenta una fenestra central grande, y que solo los terguitos VIII y IX están marginados, lo que lo distinguiría de $B$. ornatissima. Coincidimos con Hopkins y Clay (1952) en considerarla a nivel específico, ya que originalmente se describió como "Nirmus ornatissimus var. xanthocephali".

HoSPEDADOR TIPO: Xanthocephalus xanthocephalus (Bonaparte, 1826).

Brueelia mauroi $\mathrm{sp} . \mathrm{n}$.

(Figs. 54 a 57, 93, 110, 112 y 113)

Material examinado: Holotipo $\sigma^{\pi}$, Alotipo $\$, 20^{\pi} \sigma^{\pi}$ y 1 , Paratipos, ex Tangavius aeneus aeneus, Fredericksburg, Virginia (NMNH).

\section{DESCRIPCIÓN:}

Macho: Aspecto general como en la figura 54. Cabeza subtriangular, con un borde preantenal apenas convexo. Carena marginal de desarrollo mediano, internamente sinuosa y pigmentada en $3 / 4$ de su longitud. La mácula del borde pulvinar de la sutura frontoclipeal ocupa $2 / 3$ de su longitud. Área nodal 


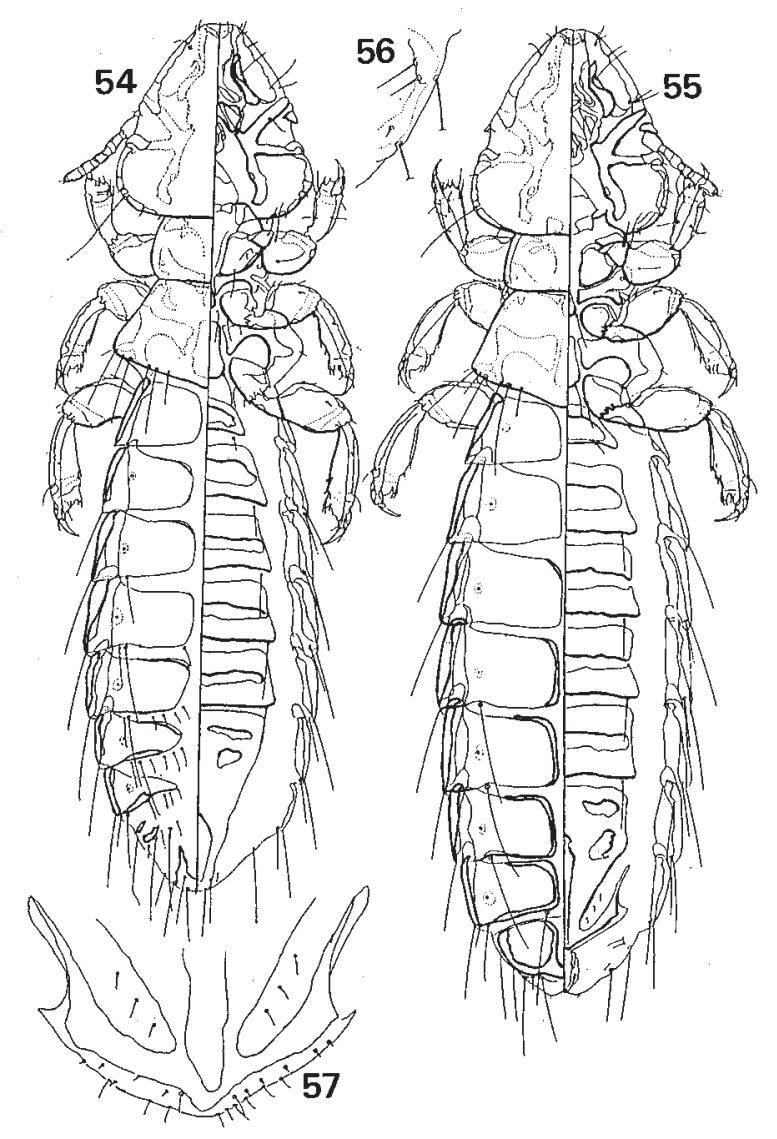

Figs. 54-57.- Brueelia mauroi: 54) macho, 55) hembra, 56) gonapófisis, 57) vulva.

Figs. 54-57.- Brueelia mauroi: 54) male, 55) female, 56) gonapophysis, 57) vulva.

de la sutura frontoclipeal fuertemente oscurecida, aclarándose algo hacia la zona genal. Área subgenal y suturas hipostomal, occipital y postoccipital anchamente pigmentadas. Carena temporal pigmentada en toda su extensión. Apodemas pro y pterotorácicos de mediano desarrollo. Placa mesosternal alargada, mediana, metasternal grande, subrectangular. Borde posterior del pterotórax sin marginación. Terguitos III-V angostamente marginados en su borde anterior; VI-VII en borde anterior y posterior y VIII en su borde posterior; Quetotaxia tergal: setas suturales pequeñas en V-VIII; IV con una seta postespiracular mediana; V-VII con una posterior larga y una accesoria mediana; $\mathrm{V}$ sin setas tergales posteriores y VI-VII con tres cada uno. Quetotaxia paratergal: II, 0; III, 1; IV-VIII, 2. Esternitos II-VI fenestrados y II y III de modo muy amplio, pero la totalidad de ellos tienen las porciones anterior y posterior en contacto por sus bordes laterales. Placa subgenital con una fenestra central amplia, y dos fenestras laterales a cada lado, de las que la superior es más transversa. Genitalia (Fig. 110): placa basal amplia, de bordes laterales poco cóncavos; parámeros bastante anchos; escleritos laterales del complejo endomeral con su borde posterior provisto de una hilera de 8-9 tubérculos medianos, habiendo una segunda hilera de aspecto semejante en su cara inferior; longitud máxima 0,138-0,165, anchura máxima 0,066-0,078.

Hembra: como en la figura 55. Aspecto general semejante al del macho, difiriendo en tamaño, medidas, terminalia y quetotaxia abdominal. Quetotaxia tergal igual a la del macho. Vulva (Fig. 57) con cinco setas espiniformes y una delgada a cada lado, y la hilera inferior con 3-6 delgadas a cada lado. Gonapófisis (Fig. 56) con dos setas. Placa subgenital con una amplia fenestra central que se abre posteriormente, y dos fenestras laterales medianas a cada lado.

$\begin{array}{lcc}\text { MEDIDAS CORPORALES: } & & \\ & \text { Macho } & \text { Hembra } \\ \text { Longitud de la cabeza } & 0,300-0,352 & 0,337-0,375 \\ \text { Anchura preantenal } & 0,242-0,266 & 0,262-0,282 \\ \text { Anchura temporal } & 0,281-0,337 & 0,303-0,341 \\ \text { Longitud del protórax } & 0,120-0,142 & 0,135-0,150 \\ \text { Anchura del protórax } & 0,172-0,206 & 0,180-0,232 \\ \text { Longitud del pterotórax } & 0,165-0,180 & 0,165-0,195 \\ \text { Anchura del pterotórax } & 0,295-0,325 & 0,307-0,367 \\ \text { Longitud del abdomen } & 0,772-0,840 & 1,050-1,087 \\ \text { Ancho del abdomen } & 0,356-0,405 & 0,424-0,461 \\ \text { Longitud total } & 1,398-1,530 & 1,624-1,757\end{array}$

HOSPEDADOR TIPO: Tangavius aeneus aeneus (Wagler, 1829).

OBSERVACIONES: hembra semejante a $B$. trinidadensis, pero se separa por la forma de la cabeza, terguitos mucho más largos y marginados de pardo desde el V, suturas occipital y postoccipital mucho menos pigmentadas, placa subgenital con una amplia fenestra medial, número muy inferior de setas espiniformes en la vulva (5 en mauroi, 9-10 en trinidadensis). Las mayores afinidades parece tenerlas con las especies de este género parásitas de Molothrus.

Brueelia emersoni sp. $n$.

(Figs. 58 a 61, 92, 108, 121 y 122)

Material eXAminado: Holotipo $0^{x}$, Alotipo $\&, 40^{x} 0^{x}$ y 6 우 $ᄋ$, Paratipos, ex Euphagus carolinus (P.L.S. Mueller). 3,5 millas al norte de Juneau, Alaska, 12-V-1951, Col. R.B. Williams (NMNH). 


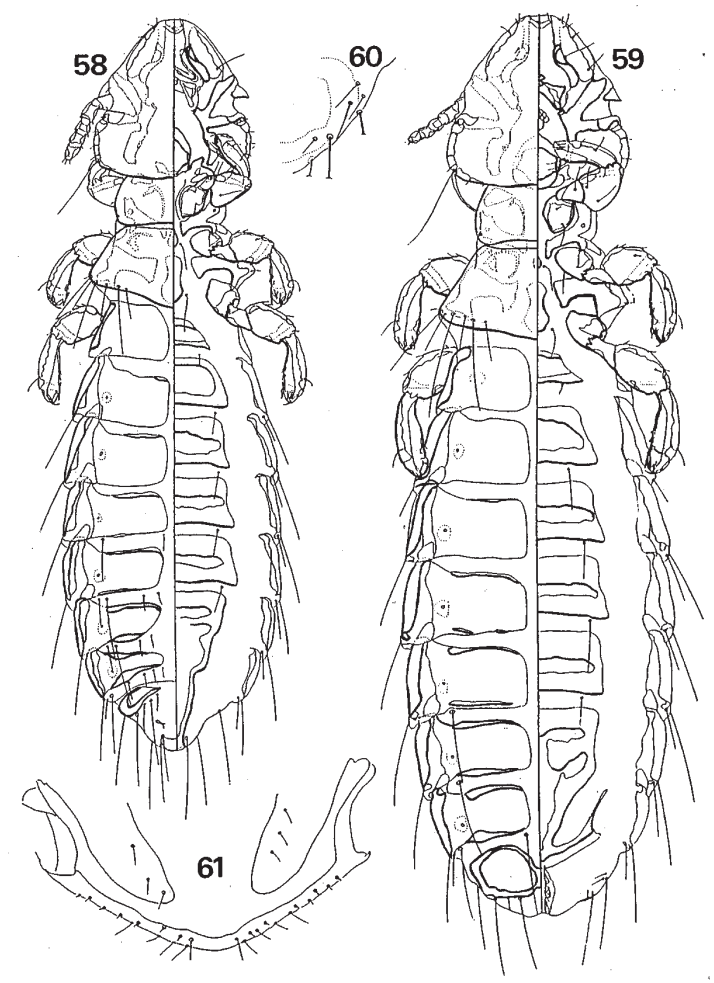

Figs. 58-61.- Brueelia emersoni: 58) macho, 59) hembra, 60) gonapófisis, 61) vulva.

Figs. 58-61.- Brueelia emersoni: 58) male, 59) female, 60) gonapophysis, 61) vulva.

\section{DESCRIPCIÓN:}

Macho: aspecto general como en la figura 58. Cabeza subtriangular, apenas más larga que ancha. Borde preantenal levemente convexo. Carena marginal espesa, estando pigmentada su mitad interna, su margen interno sinuoso. No se aprecia con claridad la inserción de los musculos cibariales. Carena temporal bien desarrollada y pigmentada. Área nodal de la sutura frontoclipeal muy oscurecida, pero el pigmento se ditribuye en una franja que se angosta hacia el borde externo y termina antes de llegar a él. La mácula del borde pulvinar de la sutura frontoclipeal ocupa aproximadamente 3/5 de su longitud. Placa gular muy característica recordando a la de B. ornatissima. Apodemas pro y pterotorácicos fuertemente pigmentados. Placa mesosternal pequeña, subpiriforme, metasternal alargada, con sus bordes laterales muy cóncavos. Borde posterior del pterotórax sin marginación. Terguitos abdominales II-IV angostamente marginados en su borde anterior; V-VIII en bordes anterior y posterior. Quetotaxia tergal: setas suturales pequeñas en VVIII; una seta postespiracular mediana en V; VIVII con una seta postespiracular larga y una accesoria mediana y además una tergal posterior pequeña cada uno. Paraterguitos fuertemente pigmentados. Quetotaxia paratergal: II, 0; III, 1-2; IV-VIII, 2. Esternitos II-VI fenestrados, el V tiene sus porciones anterior y posterior separadas; el III está ampliamente fenestrado, pero en contacto lateralmente; IV-VI con fenestras angostas y muy transversas. Placa subgenital con una fenestra central que coalesce con las laterales, tomando un aspecto muy irregular. Genitalia (Fig. 108): placa basal relativamente angosta y poco cóncava lateralmente; parámeros moderadamente anchos. Escleritos laterales del complejo endomeral con su borde posterior provisto de 7-8-mamelones, y en su cara inferior se insinúa apenas una segunda hilera con tres mamelones pequeños; longitud máxima 0,1230,165 , anchura máxima 0,069-0,075.

Hembra: aspecto general (Fig. 59) semejante al macho, difiriendo en tamaño, medidas, terminalia y quetotaxia abdominal. Quetotaxia paratergal semejante a la del macho. Vulva (Fig. 61) con 6-7 setas espiniformes y una delgada a cada lado; hilera inferior con 3-4 setas delgadas; gonapófisis con dos setas robustas y una delgada (Fig. 60). Placa subgenital (Fig. 92) con una fenestra central que no llega al borde posterior y dos fenestras laterales medianas, de las que las superiores son más transversas.

MEDIDAS CORPORALES:

$\begin{array}{lcc} & \text { Machos } & \text { Hembras } \\ \text { Longitud de la cabeza } & 0,330-0,352 & 0,345-0,375 \\ \text { Anchura preantenal } & 0,262-0,285 & 0,280-0,307 \\ \text { Anchura temporal } & 0,319-0,345 & 0,345-0,379 \\ \text { Longitud del protórax } & 0,135-0,150 & 0,150-0,162 \\ \text { Anchura del protórax } & 0,225-0,232 & 0,229-0,247 \\ \text { Longitud del pterotórax } & 0,165-0,187 & 0,170-0,195 \\ \text { Anchura del pterotórax } & 0,337-0,356 & 0,364-0,386 \\ \text { Longitud del abdomen } & 0,892-0,982 & 1,024-1,222 \\ \text { Anchura del abdomen } & 0,442-0,495 & 0,472-0,555 \\ \text { Longitud total } & 1,547-1,740 & 1,776-1,917\end{array}$

HosPedADOR TIPO: Euphagus carolinus (P.L.S. Mueller, 1776).

OBSERVACIONES: Unicamente puede aproximarse a $B$. flinti de la que se distingue inmediatamente por la forma de la cabeza, distribución del pigmento en la placa gular, falta de marginación parduzca en los hemiterguitos del segmento II, y fenestras de los esternitos II-VI y placas subgenitales de ambos sexos notablemente más pronunciadas. 


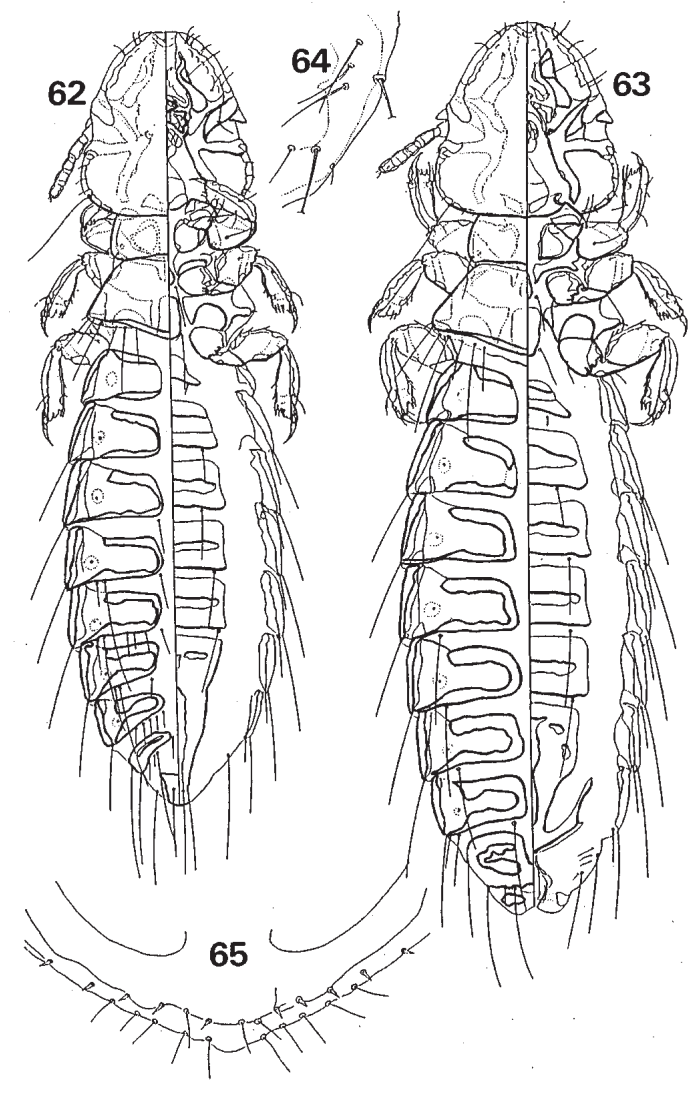

Figs. 62-65.- Brueelia marcoi, 62) macho, 63) hembra, 64) gonapófisis, 65) vulva.

Figs. 62-65.- Brueelia marcoi, 62) male, 63) female, 64) gonapophysis, 65) vulva.

Brueelia marcoi sp. $\mathrm{n}$.

(Figs. 62 a 65, 91, 104 y 129)

Material examinado: Holotipo $0^{x}$, Alotipo $\&$, $70^{x} 0^{x}$ y 13 우 옹 Paratipos, ex Curaeus curaeus curaeus (Molina). Huilmo, Coquimbo, Chile, M.A. Marín (MLP); 3 ㅇ , ex Curaeus curaeus reynoldsi (Sclater), isla de los Estados, Argentina (KCE).

\section{DESCRIPCIÓN:}

Macho: aspecto general como en la figura 62. Cabeza suboval, más larga que ancha. Borde preantenal convexo, semejante al de $B$. oxypyga. Carena marginal de normal desarrollo, internamente sinuosa y pigmentada en 3/4 de su extensión; su pigmentación se prolonga en un tono más claro hasta las inserciones de los musculos cibariales, los que son bastante visibles. La mácula del borde pulvinar de la sutura frontoclipeal ocupa algo más de $2 / 3$ de su longitud. Área nodal de la sutura frontoclipeal muy oscura, aclarándose algo hacia la zona genal. Área subgenal y suturas hipostomal, occipital y postoccipital moderadamente pigmentadas. Carena temporal levemente pigmentada en toda su extensión. Apodemas pro y pterotorácicos desarrollados y pigmentados. Placa mesosternal mediana, piriforme, la metasternal grande, subrectangular. Borde posterior del pterotórax marginado de parduzco. La totalidad de los terguitos abdominales marginados en sus bordes anterior y posterior y III-VIII también en su borde interno o sutural. Paraterguitos pardo-oscuros, bastante anchos, siendo su quetotaxia: II, 0; III-VIII, 2. Quetotaxia tergal: suturales desde pequeñas hasta casi medianas en IV-VIII; una postespiracular larga y una accesoria mediana en V-VII; V sin tergales posteriores y VI-VII con 2-3 a cada lado. Esternitos III-VI angostamente fenestrados transversalmente. Placa subgenital con una gran fenestra central alargada y 1-2 fenestras laterales pequeñas. Genitalia (Fig. 104): placa basal alargada, poco cóncava lateralmente; parámeros pigmentados, largos. Escleritos laterales del complejo endomeral amplios, con su borde posterior provisto de una hilera de 12-14 tubérculos pequeños, de aspecto aserrado; longitud máxima 0,226-0,236, anchura máxima 0,096.

Hembra: como en la figura 63. Aspecto general semejante al del macho, difiriendo en tamaño, medidas, terminalia y quetotaxia abdominal. Quetotaxia paratergal igual a la del macho. Vulva (Fig. 65) con unas cinco setas cortas espiniformes y 1-2 delgadas a cada lado, y la hilera inferior con cinco setas medianas a cada lado. Gonapófisis (Fig. 64) con tres setas. Placa subgenital con una amplia fenestra central longitudinal (Fig. 91) y dos fenestras laterales pequeñas e irregulares a cada lado. Pigmentacion del terguito IX muy característico (Fig. 63), y la del XI consistente en una mácula de mediano desarrollo.

$\begin{array}{lcc}\text { MEDIDAS CORPORALES: } & & \\ \text { Longitud de la cabeza } & 0,430-0,441 & 0,441-0,463 \\ \text { Anchura preantenal } & 0,339-0,366 & 0,376-0,420 \\ \text { Anchura temporal } & 0,389-0,409 & 0,414-0,430 \\ \text { Longitud del protórax } & 0,150-0,172 & 0,161-0,172 \\ \text { Anchura del protórax } & 0,269 & 0,269-0,290 \\ \text { Longitud del pterotórax } & 0,193-0,204 & 0,226-0,236 \\ \text { Anchura del pterotórax } & 0,393-0,430 & 0,430-0,463 \\ \text { Longitud del abdomen } & 1,044-1,173 & 1,270-1,335 \\ \text { Anchura del abdomen } & 0,508-0,570 & 0,570-0,635 \\ \text { Longitud total } & 1,787-1,949 & 2,035-2,154\end{array}$

HoSPEDADOR TIPO: Curaeus curaeus curaeus (Molina, 1782).

OBSERVACIONES: Hembra semejante a $B$. oxypyga, pero fácilmente saparable de ella por la distibucion 

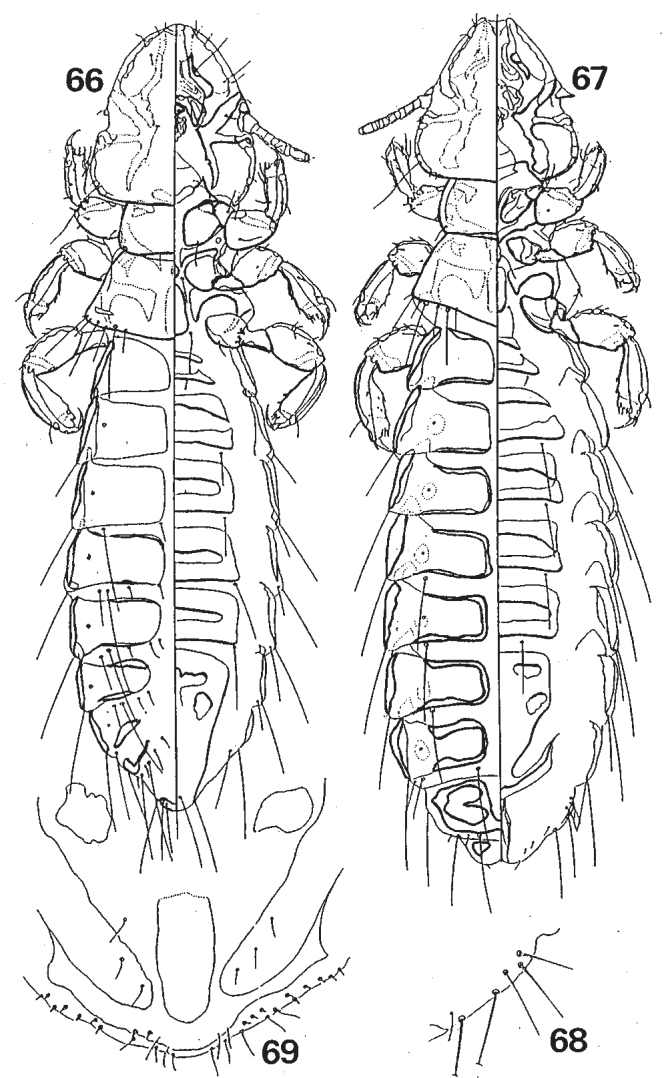

Figs. 66-69.- - 66) Brueelia americana, macho; 67-69) B. trinidadensis: 67) hembra, 68) gonapófisis, 69) vulva.

Figs. 66-69.-66) Brueelia americana, male; 67-69) B. trinidadensis: 67) female, 68) gonapophysis, 69) vulva.

del pigmento y fuerte marginación de los terguitos, fenestración de los esternitos y placa subgenital, vulva y por sus medidas.

Brueelia trinidadensis sp. $\mathrm{n}$. (Figs. 67 a 69, 95 y 114)

Material eXAminado: Holotipo $ᄋ$ y 1 , Paratipo, ex Molothrus bonariensis minimus Dalmas, Coalmine, Trinidad, 12-XII-1958, col. Aitken \& Downs (NMNH).

\section{DESCRIPCIÓN:}

Macho: desconocido.

Hembra: aspecto general como en la figura 67. Cabeza subtriangular, borde preantenal con sus márgenes apenas convexos; carenas marginales con su mitad interna oscurecida; área nodal de la sutura clipeofrontal con una gran mácula negruzca.
Mácula del borde pulvinar de la sutura clipeofrontal ocupando aproximadamente la mitad de su longitud. Postgena, sutura hipostomal, suturas occipital y postoccipital anchamente oscurecidas. Carenas temporales pigmentadas. Apodemas protorácicos de mediano desarrollo, pigmentados, al igual que los pterotorácicos. Placa prosternal desarrollada, ovoide, metasternal amplia, subcuadrilátera. Terguitos II-VIII con sus márgenes anterior y posterior pigmentados, IV-VIII también pigmentados en su borde sutural; IX con silueta pigmentada característica; X-XI con una pequeña mácula a cada lado. Esternitos II-VI ampliamente fenestrados medialmente, y en II-IV sus tercios anterior y posterior no llegan a veces a tocarse. Placa subgenital con cuatro fenestras o áreas hialinas pequeñas (Fig. 95) y una fenestra central posterior mal definida. Vulva (Fig. 69) con 8-10 setas espiniformes y 1-2 delgadas a cada lado; hilera inferior con 4-5 setas delgadas. Gonapófisis con tres setas (Fig. 68). Terguitos X-XI con una mácula a cada lado.

MEDIDAS CORPORALES:

$\begin{array}{lr}\text { Longitud de la cabeza } & 0,345-0,349 \\ \text { Anchura preantenal } & 0,266-0,270 \\ \text { Anchura temporal } & 0,330-0,337 \\ \text { Longitud del protórax } & 0,150-0,257 \\ \text { Anchura del protórax } & 0,217-0,222 \\ \text { Longitud del pterotórax } & 0,180-0,187 \\ \text { Anchura del pterotórax } & 0,337-0,345 \\ \text { Longitud del abdomen } & 0,997-1,080 \\ \text { Anchura del abdomen } & 0,469-0,472 \\ \text { Longitud total } & 1,643-1,724\end{array}$

HOSPEDADOR TIPO: Molothrus bonariensis minimus Dalmas, 1900.

OBSERVACIONES: Especie muy distinta por la totalidad de sus caracteres de $B$. bonariensis sp. n. cuyo hospedador es $M$. bonariensis bonariensis (Gmelin, 1789). Probablemente el hecho de hallarse su hospedador confinado a la isla de Trinidad sea la razón de su notable diferenciación respecto de aquella especie.

\section{Brueelia americana $\mathrm{sp} . \mathrm{n}$. \\ (Figs. 66 y 111)}

Material eXaminado: Holotipo $\sigma^{\pi}$, ex Molothrus ater ater (Boddaert), Lincoln, Nebraska, USA, sin fecha, col. M.A. Carriker, Jr. (NMNH).

\section{DESCRIPCIÓN:}

Macho: aspecto general como en la figura 66. Cabeza suboval; borde preantenal anchamente parabólico; carena marginal en sus $4 / 5$ partes pig- 
mentada, extendiéndose la pigmentación algo hacia la parte discal. Mácula del borde pulvinar de la sutura clipeofrontal abarcando 3/4 de su longitud. Área nodal de la sutura clipeofrontal con pigmentación de mediano desarrollo. Trabéculas muy pequeñas. Área postgenal y suturas hipostomal, occipital $\mathrm{y}$ postoccipital angostamente pigmentadas. Apodemas protorácicos de mediano desarrollo, al igual que los pterotorácicos. Pterotórax con una pequeña mácula alargada en su borde posterior, situada hacia el lado externo. Terguitos II-IV despigmentados; I-VII con sus márgenes anterior y posterior angostamente pigmentados; VIII solamente en su margen posterior y IX en su margen posterior y externo. Esternitos II-III ampliamente fenestrados, no contactando entre si sus extremos anterior y posterior; IV-VI con sus tercios anterior y posterior unidos. Placa subgenital con un forámen irregular medial y uno más pequeño a cada lado. Paraterguitos angostos, cuya quetotaxia es: II, 0; III, 1; IV-VII, 2. Terguito VI con dos setas tergales posteriores, VII con una (ocasionalmente también en V). Genitalia (Fig. 111) con placa basal angosta y alargada, poco cóncava lateralmente, escleritos laterales del complejo endomeral con unas cinco hileras de tubérculos en su cara inferior; longitud máxima 0,204, anchura máxima 0,075.

MEDIDAS CORPORALES:

$\begin{array}{ll}\text { Longitud de la cabeza } & 0,376 \\ \text { Anchura preantenal } & 0,290 \\ \text { Anchura temporal } & 0,266 \\ \text { Longitud del protórax } & 0,129 \\ \text { Anchura del protórax } & 0,236 \\ \text { Longitud del pterotórax } & 0,204 \\ \text { Anchura del pterotórax } & 0,366 \\ \text { Longitud del abdomen } & 1,044 \\ \text { Anchura del abdomen } & 0,463 \\ \text { Longitud total } & 1,777\end{array}$

Hembra: desconocida.

HOSPEDADOR TIPO: Molothrus ater ater (Boddaert, 1783).

OBSERVACIONES: Especie bien distinta a todas las restantes aquí estudiadas como parásitas del género Molothrus por la forma de la cabeza, medidas, distribución de la pigmentación y genitalia del macho.

\section{Brueelia bonariensis $\mathrm{sp} . \mathrm{n}$.}

(Figs. 70 a 73, 98, 103, 124 y 125)

Material eXaminado: Holotipo $\sigma^{\pi}$, Alotipo $\odot$ y $10^{\pi}$, Paratipo, ex Molothrus b. bonariensis (Gmelin), Castelli, prov. Buenos Aires, Argentina, IX-1970; 10", Paratipo, mismo hospedador,

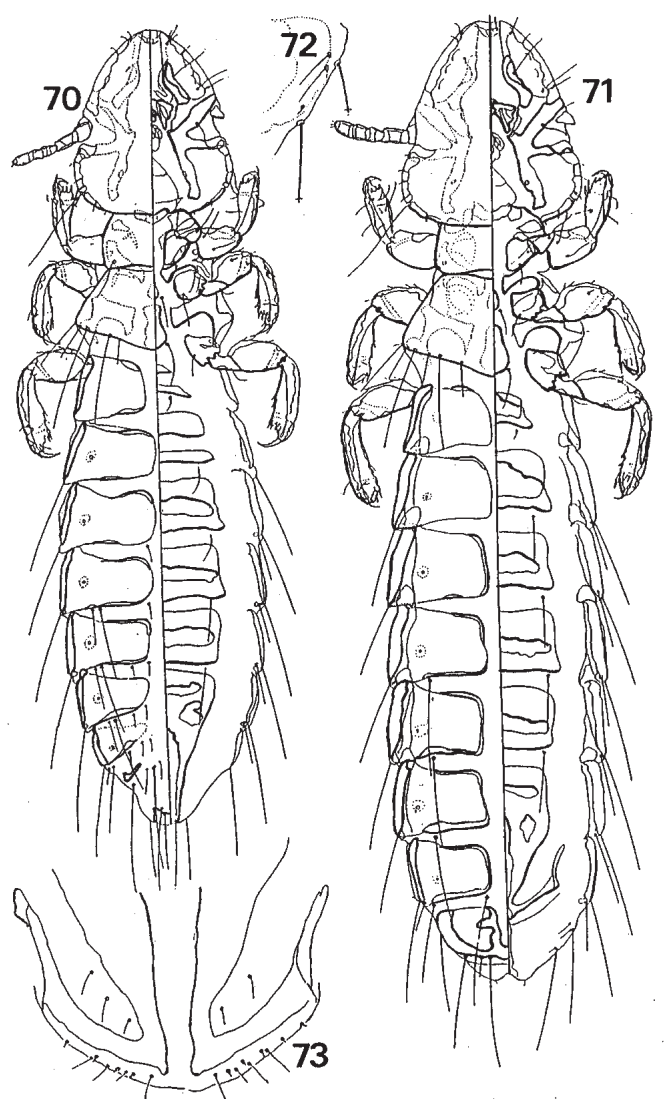

Figs. 70-73.- Brueelia bonariensis: 70) macho, 71) hembra, 72) gonapofisis, 73) vulva.

Figs. 70-73.- Brueelia bonariensis: 70) male, 71) female, 72) gonapophysis, 73) vulva.

Gral. Otamendi, Prov. Buenos Aires, Argentina, IX-1981; 3 $0^{x} \sigma^{x}, 1$ 옹, Paratipos, Lincoln, prov. Buenos Aires, Argentina, XI-1980 (KCE y MLP); $100^{7} 0^{7}, 10$ 우 옹, Paratipos, Partido Magdalena, prov. Buenos Aires, Argentina, 6-X-1984; $10^{7}$ ApaMi, Bella Vista, Paraguay.

\section{DESCRIPCIÓN:}

Macho: aspecto general como en la figura 70. Cabeza suboval, alargada; borde preantenal convexo, casi parabólico. Carena marginal de desarrollo normal, internamente sinuosa y pigmentada en 3/4 de su longitud; su pigmentación apenas se extiende hacia la inserción de los músculos cibariales, visibles en número de 2-3. Mácula del borde pulvinar de la sutura frontoclipeal ocupando más de la mitad de su longitud. Área nodal de la sutura frontoclipeal fuerte pero angostamente pigmentada, aclarándose hacia la zona genal. Zona subgenal y suturas hipostomal, occipital y postoccipital moderada- 
mente pigmentadas en toda su extensión. Apodemas pro y pterotorácicos de desarrollo normal. Placa mesosternal mediana, ovoide; Placa metasternal más amplia, con sus bordes laterales cóncavos e irregularmente sinuosos. Terguitos IIVI angostamente marginados en sus bordes anterior y posterior; VII y IX sólo en su borde posterior. Quetotaxia tergal: suturales pequeñas en IV-VIII con una postespiracular larga y una accesoria mediana cada uno; VI-VII con una tergal posterior pequeña cada uno. Paraterguitos angostos, bien pigmentados, y cuya quetotaxia es: II, 0; III, 1; IVVIII, 2. Esternitos II-VI fenestrados; II-III con sus porciones anterior y posterior no en contacto; IV-VI con fenestra angosta y transversa, y siempre sus porciones anterior y posterior en contacto. Placa subgenital con una gran fenestra central alargada y dos fenestras laterales de las que las dos superiores a menudo coalescen entre sí, dando una fenestra transversa única próxima al borde anterior. Genitalia: de tamaño pequeño; placa basal con sus márgenes laterales cóncavos; parámeros pigmentados. Escleritos laterales del complejo endomeral tipicos e irregularmente pigmentados (Fig. 103), con su borde posterior con unas 9-11 pequeñas denticulaciones en una hilera única; longitud máxima 0,150-0,153, anchura máxima 0,053-0,064.

Hembra: como en la figura 71. Aspecto general semejante al del macho, difiriendo en tamaño, medidas, terminalia y quetotaxia abdominal. Vulva (Fig. 73) con unas cinco setas espiniformes (raramente cuatro) y una seta delgada a cada lado. Placa subgenital con una amplia fenestra central alargada, que suele llegar hasta el borde posterior, y dos fenestras laterales de las que las dos superiores a menudo coalescen entre sí, lo mismo que las dos inferiores, dando fenestras transversas (Fig. 98). Gonapófisis como en la figura 72 .

\section{MEDIDAS CORPORALES:}

$\begin{array}{lcc} & \text { Machos } & \text { Hembras } \\ \text { Longitud de la cabeza } & 0,376-0,387 & 0,420-0,430 \\ \text { Anchura preantenal } & 0,258-0,269 & 0,290-0,301 \\ \text { Anchura temporal } & 0,323-0,333 & 0,366-0,376 \\ \text { Longitud del protórax } & 0,129-0,140 & 0,151-0,161 \\ \text { Anchura del protórax } & 0,215-0,226 & 0,236 \\ \text { Longitud del pterotórax } & 0,172-0,183 & 0,204 \\ \text { Anchura del pterotórax } & 0,333-0,344 & 0,366-0,398 \\ \text { Longitud del abdomen } & 0,947-0,990 & 1,217-1,292 \\ \text { Anchura del abdomen } & 0,376-0,430 & 0,463-0,484 \\ \text { Longitud total } & 1,583-1,669 & 1,917-1,981\end{array}$

HOSPEDADOR TIPO: Molothrus bonariensis bonariensis (Gmelin, 1789).

OBSERVACIONES: el macho se aproxima a $B$. americana, pero se diferencia claramente de él por la

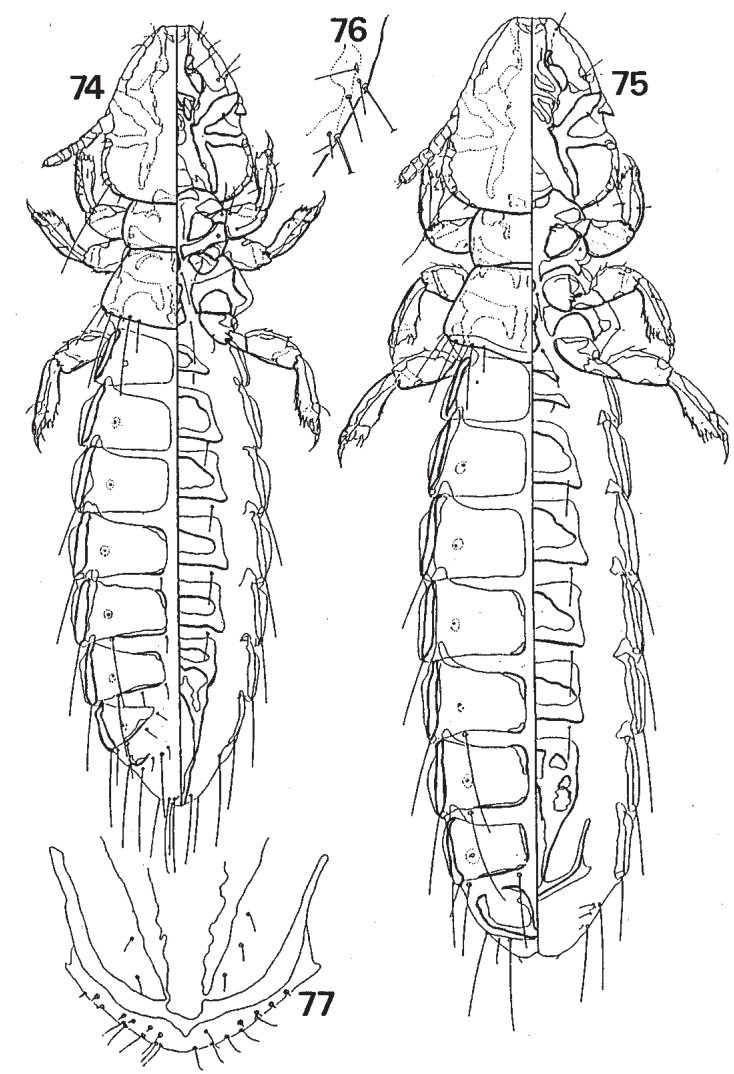

Figs. 74-77.- Brueelia badia: 74) macho, 75) hembra, 76) gonapófisis, 77) vulva.

Figs. 74-77.-Brueelia badia: 74) male, 75) female, 76) gonapophysis, 77) vulva.

forma de la cabeza, terguitos II-IV marginados de parduzco y falta de seta postespiracular en el terguito IV.

Brueelia badia sp. $\mathrm{n}$.

(Figs. 74 a 77, 96, 109, 127 y 128)

Material EXAminado: Holotipo $0^{x}$, Alotipo $ᄋ$ y $30^{x} 0^{x}$ y 3 ㅇ \&, Paratipos, Lincoln, prov. Buenos Aires, Argentina; $20^{\pi} \sigma^{\pi}$ y 3 \& $\&$, Paratipos, Gral. Otamendi, prov. Buenos Aires, Argentina, IX-1981; 10 $0^{\star}$, Paratipo, Magdalena, prov. Buenos Aires, Argentina, 1985; $160^{7} 0^{7}$ y 36 ㅇ ㅇ, Gral. Mansilla, partido de Magdalena, prov. Buenos Aires, Argentina, 9-VII-1985 (MLP y NMNH).

\section{DESCRIPCIÓN:}

Macho: aspecto general como en la figura 74 . Cabeza alargada, suboval. Borde preantenal levemente convexo, casi parabólico. Carena marginal 


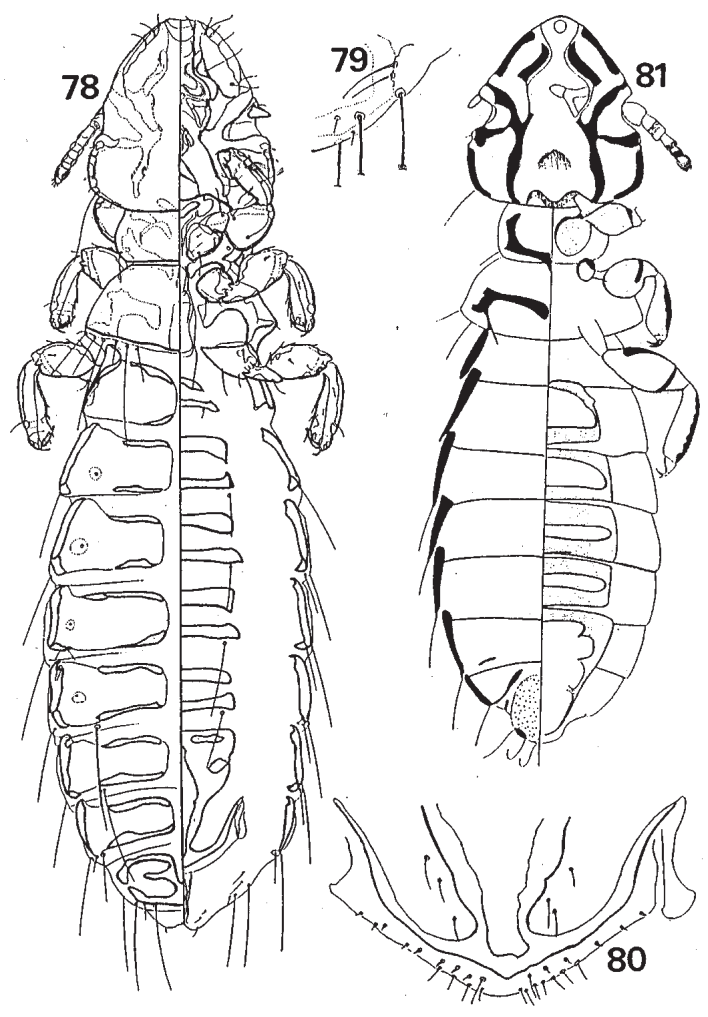

Figs. 78-81.- Brueelia oxypyga: 78) hembra, 79) gonapófisis, 80) vulva; 81) B. sallei, macho (de Carriker, 1963).

Figs. 78-81.- Brueelia oxypyga: 78) female, 79) gonapophysis, 80) vulva; 81) B. sallei, male (from Carriker, 1963).

desarrollada, internamente sinuosa y pigmentada en 3/4 de su longitud. Mácula del borde pulvinar de la sutura frontoclipeal pequeña, no ocupando más de $1 / 3$ de su longitud, y desplazada hacia el borde labral. Improntas de los músculos cibariales no evidentes. Área nodal de la sutura frontoclipeal muy oscurecida, aclarándose algo hacia la zona genal. Área subgenal y suturas occipital, postoccipital e hipostomal moderadamente pigmentadas. Carena temporal casi totalmente pigmentada. Apodemas pro y pterotorácicos de moderado desarrollo. Placa mesosternal muy alargada y angosta; metasternal no muy desarrollada, con bordes laterales cóncavos e irregularmente sinuosos, y puede presentar una fenestración central irregular. Borde posterior del pterotórax carente de marginación. Terguitos abdominales V-VII con angosta y reducida marginación en sus bordes anterior y posterior; VIII solamente marginado en su borde posterior; IX muy reducido.

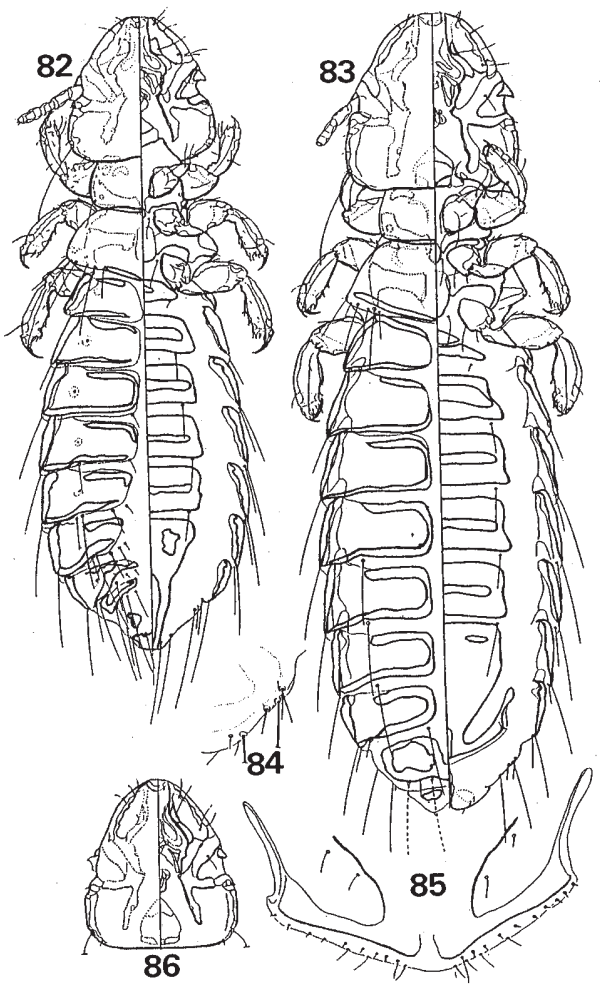

Figs. 82-86.- Brueelia flinti: 82) macho, 83) hembra, 84) gonapofisis, 85) vulva, 86) cabeza hembra de Casidix m. mexicanus.

Figs. 82-86.- Brueelia flinti: 82) male, 83) female, 84) gonapophysis, 85) vulva, 86) head female from Casidix m. mexicanus.

Quetotaxia tergal: suturales pequeñas en V-VIII; VIVII con una seta postespiracular larga y $0-1$ setas tergales posteriores, sin setas accesorias. Paraterguitos bien pigmentados y de moderado desarrollo; su quetotaxia es: II-III, 0; IV-VIII, 1. Esternitos II-VI ampliamente fenestrados, pero siempre sus porciones anterior y posterior en contacto por sus laterales. Placa subgenital con una o dos fenestras centrales alargadas y dos laterales a cada lado de las que las dos superiores pueden presentar coalescencia entre sí y con la fenestra central superior, y las dos inferiores son mucho más amplias y alargadas, y tambien pueden estar en contacto con la fenestra central superior. Genitalia: placa basal angostada anteriormente y notablemente cóncava lateralmente; parámeros pigmentados, escleritos laterales del complejo endomeral con su margen posterior terminado en una hilera de 3-4 tubérculos notables (Fig. 109); longitud máxima 0,161 , anchura máxima 0,053 . 

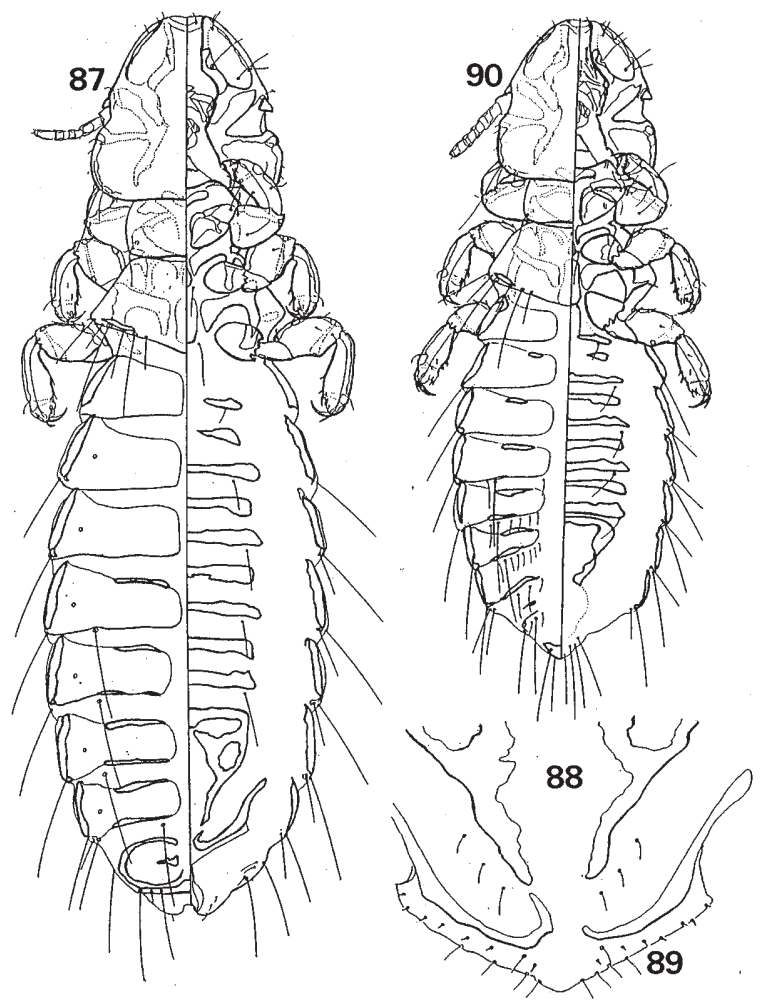

Figs. 87-90.- Brueelia mimas: 87) hembra, 88) terminación placa subgenital, 89) vulva, 90) macho.

Figs. 87-90.- Brueelia mimas: 87) female, 88) end of subgenital plate, 89) vulva, 90) male.

Hembra: como en la figura 75. Aspecto general semejante al del macho. Setas postespiraculares largas presentes en VI-VII. Quetotaxia paratergal igual a la del macho. Vulva (Fig. 77) con 4-6 setas espiniformes y una seta delgada a cada lado; hilera inferior con cinco setas delgadas a cada lado. Gonapófisis como en la figura 76. Placa subgenital (Fig. 96) con una gran fenestra central, dividida o no transversalmente en dos porciones, de las que la superior es más pequeña, y dos fenestras laterales a cada lado. Pigmentación del terguito IX característica, en forma de epsilon, muy abierta y acostada.

MEDIDAS CORPORALES:

Longitud de la cabeza

Anchura preantenal

Anchura temporal

Longitud del protórax

Anchura del protórax

Longitud del pterotórax

Anchura del pterotórax

$\begin{array}{cc}\text { Machos } & \text { Hembras } \\ 0,390-0,400 & 0,420-0,430 \\ 0,269 & 0,333-0,344 \\ 0,312-0,344 & 0,366-0,382 \\ 0,123-0,130 & 0,110-0,140 \\ 0,226-0,236 & 0,258-0,270 \\ 0,172-0,183 & 0,183-0,215 \\ 0,333-0,344 & 0,366-0,376\end{array}$

Longitud del abdomen $\quad 0,950-1,044 \quad 1,206-1,346$

Anchura del abdomen $\quad 0,409-0,430 \quad 0,476-0,506$

Longitud total $\quad 1,593-1,723 \quad 1,906-2,067$

HOSPEDADOR TIPO: Molothrus badius badius (Vieillot, 1819).

OBSERVACIONES: esta especie se aparta de las otras tres conocidas como parásitas de Molothrus sobre todo por la quetotaxia paratergal, con sólo una seta en IV-VIII en lugar de dos, y por la quetotaxia tergal del macho, que carece de postespiraculares en $\mathrm{V}$ y carencia de setas accesorias.

\section{Brueelia latiuscula (Kellogg \& Chapman, 1899)}

Nirmus latiusculus Kellogg \& Chapman, 1899. Occas. Pap. California Acad. Sci., 6: 90-92.

Brüelia latiuscula: Hopkins \& Clay, 1952. Checklist: 57; Carriker, 1957. Microentomology, 22(5): 101.

Brueelia latiuscula: Emerson, 1972. Checklist, Pt. I: 30.

No nos ha sido posible examinar materiales pertenecientes a esta especie.

$\mathrm{Su}$ descripción original, muy pormenorizada, nada dice acerca de la posible presencia de máculas pigmentadas en el borde pulvinar de la sutura clipeolabral, que tampoco aparecen representadas claramente en la figura acompañante (un macho), por lo que provisionalmente, y basados sobre la pigmentación de las carenas temporales, optamos por incluirla en el grupo ornatissima, subgrupo amazonae.

MEDIDAS CORPORALES (suministradas por Kellogg \& Chapman, 1899, para el holotipo macho):

$\begin{array}{ll}\text { Longitud de la cabeza } & 0,340 \\ \text { Anchura temporal } & 0,310 \\ \text { Anchura del abdomen } & 0,400 \\ \text { Longitud total } & 1,650\end{array}$

Hembra: desconocida.

HOSPEDADOR TIPO: una especie desconocida (incierta) de Icteridae; originalmente Amphispiza belli (Fringillidae) lo cual claramente representa un error.

OBSERVACIONES: distinguible por sus características de las demás especies aquí estudiadas, pero parece aproximarse al subgrupo amazonae, parásitos de Molothrus.

\section{Brueelia oxypyga (Giebel, 1874)}

(Figs. 78 a 80 y 91 )

Nirmus oxypygus Giebel, 1874. Insecta Epizoica: 135.

Brüelia oxypyga: Hopkins \& Clay, 1952. Checklist: 59. 


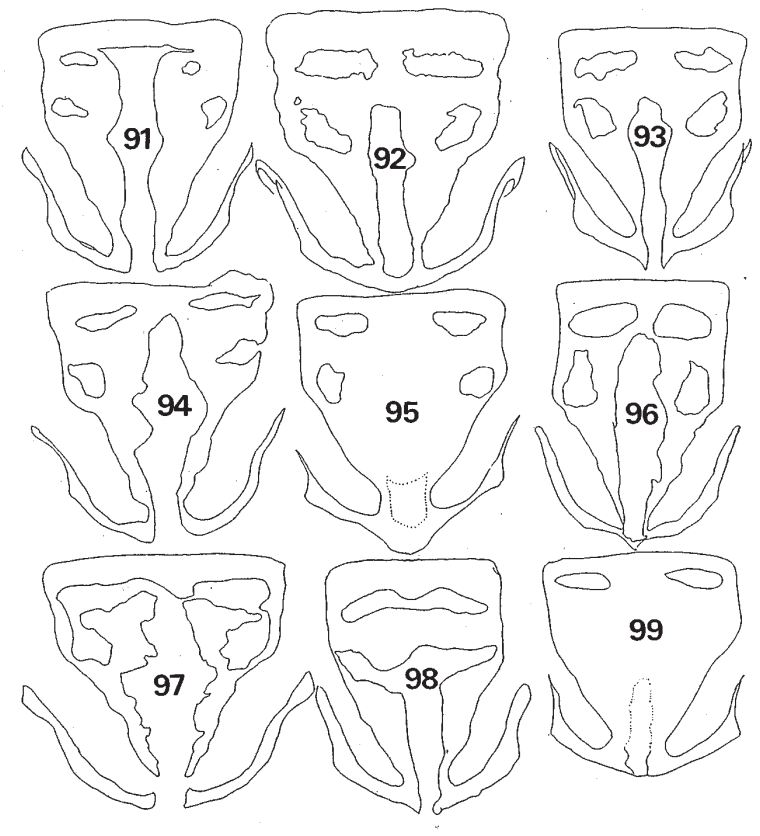

Figs. 91-99.- Placas subgenitales femeninas de 91) Brueelia marcoi; 92) B. emersoni; 93) B. mauroi; 94) B. oxppyga, 95) B. trinidadensis; 96) B. badia, 97) B. mimas; 98) B. bonariensis; 99) B. flinti.

Figs. 91-99. - Subgenital female plates of 91) Brueelia marcoi; 92) B. emersoni; 93) B. mauroi; 94) B. oxypyga, 95) B. trinidadensis; 96) B. badia, 97) B. mimas; 98) B. bonariensis; 99) B. flinti.

MATERIAL EXAMINADO: 1 우 ex Amblyramphus holosericeus (Scopoli), Partido General Lavalle, prov. Buenos Aires, Argentina, 10-I-1973, col. A.C. Cicchino (MLP).

\section{REDESCRIPCIÓN:}

Hembra: aspecto general como en la figura 78. Cabeza suboval, borde preantenal ligeramente convexo; carena marginal espesa, sinuosa, pigmentada en 3/4 partes de su extensión. Mácula del borde pulvinar de la sutura clipeofrontal ancha, ocupando más de la mitad de su longitud. Área nodal de la sutura clipeofrontal con pigmentacion de mediana extensión. Área postgenal y suturas hipostomal, occipital y postoccipital angostamente pigmentadas. Carena occipital pigmentada en $2 / 3$ de su extensión. Apodemas protorácicos bien desarrollados y pigmentados, pterotorácicos de menor desa-

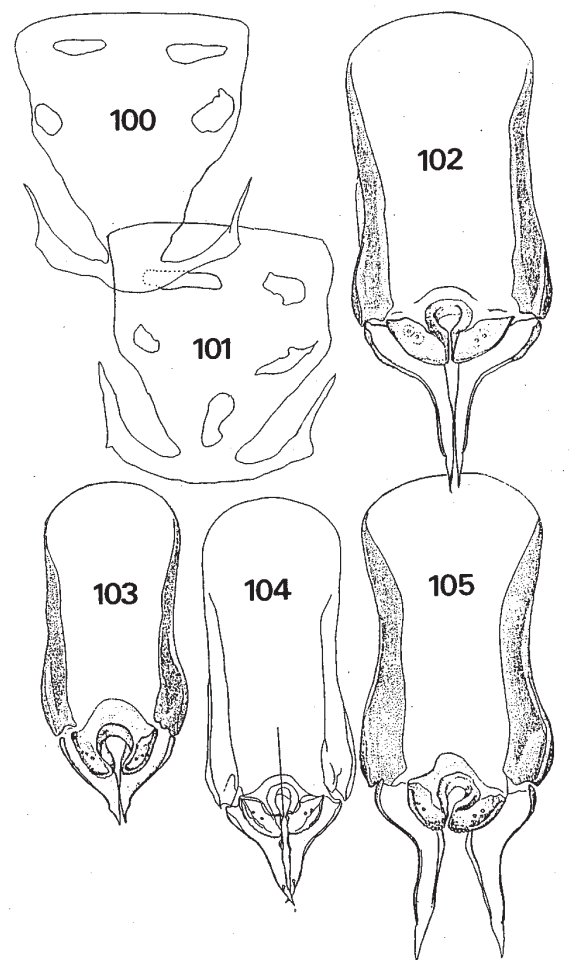

Figs. 100-105. - 100 y 101) placas subgenitales femeninas de ejemplares de Brueelia ornatissima; 102-105) genitales masculinos de 102) B. mirabile, 103) B. bonariensis, 104) B. marcoi; 105) B. mimas.

Figs. 100-105.- $100 \&$ 101) subgenital female plates of specimens of Brueelia ornatissima; 102-105) male genitalia of 102) B. mirabile, 103) B. bonariensis, 104) B. marcoi and 105) B. mimas.

rrollo. Placa mesosternal de mediano tamaño, subelíptica, metasternal grande, subcuadrilátera. Borde posterior del pterotórax con una estrecha banda pigmentada. Terguitos II-VII con sus bordes anterior y posterior pigmentados. Esternitos II-VI ampliamente fenestrados, sus tercios anterior y posterior casi nunca llegan a estar en contacto. Paraterguitos medianamente anchos, cuya quetotaxia es: II, 0; III, 1-2; IV-VII, 2. Vulva (Fig. 80): hilera superior con 5-8 setas espiniformes y una delgada, e hilera inferior con 4-7 setas delgadas más largas a cada lado; placa subgenital (Fig. 94) con una amplia fenestra central alargada irregular, y cuatro áreas laterales más pequeñas; lleva $3+3$ setas. Gonapófisis (Fig. 79) con dos setas gruesas. Pigmentación del terguito IX característica, X+XI sin máculas. 


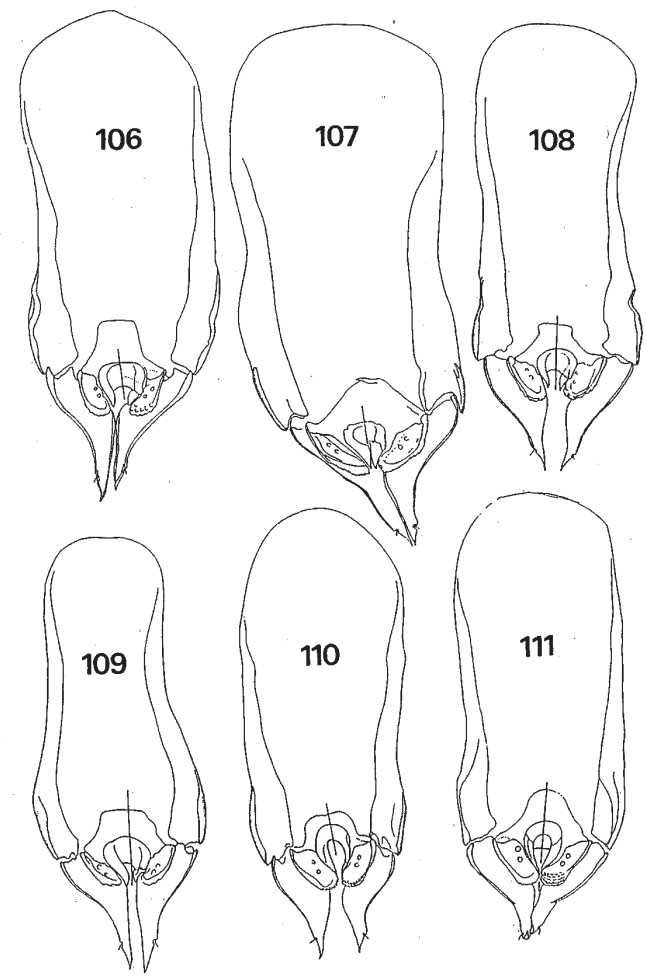

Figs. 106-111.- Genitales masculinos de 106) Brueelia ornatissima, 107) B. flinti, 108) B. emersoni; 109) B. badia, 110) B. mauroi, 111) B. americana.

Figs. 106-111. - Male genitalia of 106) Brueelia ornatissima, 107) B. flinti, 108) B. emersoni; 109) B. badia, 110) B. mauroi, 111) B. americana.

\section{MEDIDAS CORPORALES DE LA HEMBRA:}

$\begin{array}{ll}\text { Longitud de la cabeza } & 0,463 \\ \text { Anchura preantenal } & 0,333 \\ \text { Anchura temporal } & 0,430 \\ \text { Longitud del protórax } & 0,161 \\ \text { Anchura del protórax } & 0,280 \\ \text { Longitud del pterotórax } & 0,215 \\ \text { Anchura del pterotórax } & 0,441 \\ \text { Longitud del abdomen } & 1,357 \\ \text { Anchura del abdomen } & 0,624 \\ \text { Longitud total } & 2,100\end{array}$

HOSPEDADOR TIPO: Amblyramphus holosericeus (Scopoli, 1786).

OBSERVACIONES: desde su descripción original esta especie no ha sido vuelta a tratar de una manera descriptiva. Es bien reconocible respecto de sus congéneres, en especial de B. mimas sp. n. por la forma de la cabeza, ausencia de seta postespiracular en V, terguitos II-III marginados de parduzco y distribución del pigmento en la placa subgenital.
Brueelia flinti sp. n.

(Figs. 82 a 86, 99, 107 y 115 a 117)

Material examinado: Holotipo $0^{7}$ ex Cassidix mexicanus major, Cameron, La., USA, 2-XI-1941 (NMNH); Alotipo 오, mismo hospedador, Corpus Christi, Texas, USA, 29-XII-1899 $(\mathrm{NMNH}) ; 10^{7}$ ex Cassidix m. mexicanus, Tlacotalpam, México, 8-II-1940, col. M.A. Carriker Jr. (NMNH) (no incluido como paratipo).

\section{DESCRIPCIÓN:}

Macho: aspecto general como en la figura 82. Cabeza suboval, borde preantenal convexo; carena marginal espesa, sinuosa y fuertemente pigmentada. Improntas de los músculos cibariales visibles (aproximadamente tres). Mácula del borde pulvinar de la sutura frontoclipeal ocupando los $2 / 3$ de su longitud. Área nodal de la sutura frontoclipeal fuertemente oscurecida, aclarándose hacia la zona genal. Área subgenal y suturas hipostomal, occipital y postoccipital anchamente pigmentadas. Carena temporal pigmentada en toda su extensión. Apodemas pro y pterotorácicos desarrollados y pigmentados. Borde posterior del pterotórax angostamente marginado de parduzco (Fig. 82). Terguitos II-VIII marginados de pardo en sus bordes anterior y posterior. Paraterguitos fuertemente pigmentados, negruzcos. Quetotaxia: II, 0; III, 1; IV-VII, 2. Esternitos fenestrados, pero siempre contactando sus bordes anterior y posterior; II apenas fenestrado; placa subgenital con dos fenestras laterales pequeñas y una medial posterior más grande. Quetotaxia tergal: IV, una seta sutural pequeña; V, una seta postespiracular larga, una accesoria mediana y una sutural pequeña; VI-VII ídem. V presentando además 1-2 setas tergales posteriores. Genitalia: placa basal ancha, desarrollada; parámeros pigmentados; escleritos laterales del complejo endomeral fuertemente rugosos (con unos 12-14 tubérculos pequeños en una sola serie lineal) en su margen posterior (Fig. 107); longitud máxima 0,190, anchura máxima 0,087 .

Hembra: como en la figura 83: aspecto general semejante al macho, difiriendo en tamaño, medidas, terminalia y quetotaxia abdominal. Quetotaxia paratergal igual a la del macho. Vulva (Fig. 85) con 7-9 (raramente seis) setas espiniformes cortas y una delgada mediana en la hilera superior, y 3-5 delgadas medianas en la hilera inferior. Gonapófisis como en la figura 84. Placa subgenital (Fig. 99) con dos pequeñas fenestras próximas al borde anterior, y una mediana alargada y mal definida hacia su borde posterior. Una mácula a cada lado del terguito $\mathrm{X}+\mathrm{XI}$. 


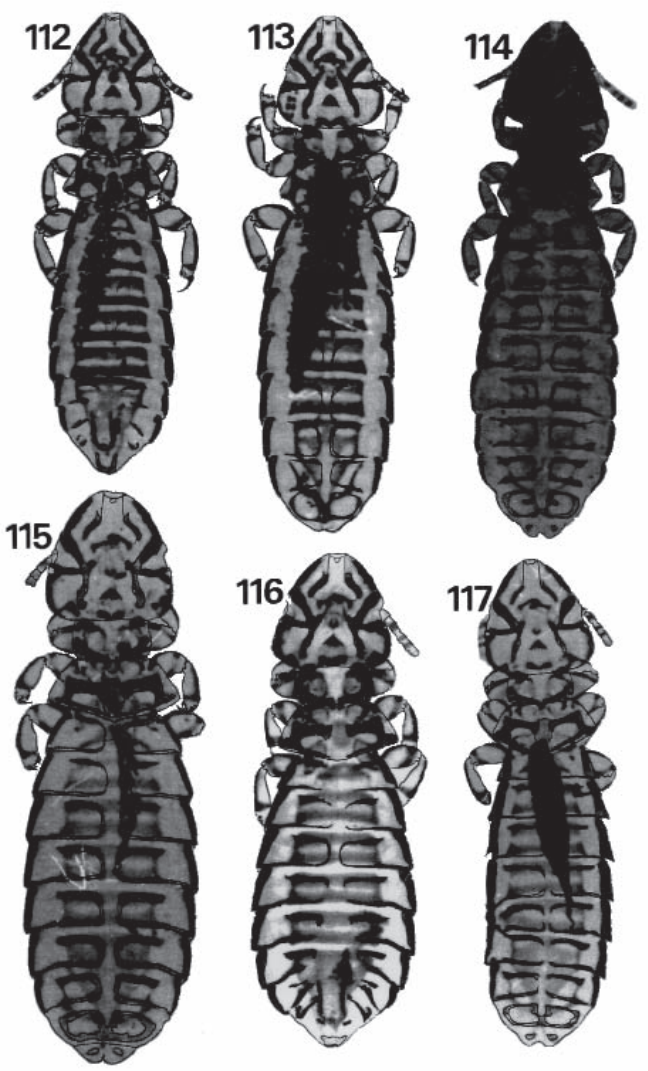

Figs.112-117.- Habitus de 112) Brueelia mauroi, macho y 113) hembra; 114) B. trinidadensis, hembra; 115) B. flinti, hembra, 116) macho y 117) hembra de Cassidix m. mexicanus.

Figs.112-117.- Habitus of 112) Brueelia mauroi, male and 113) female; 114) B. trinidadensis, female; 115) B. flinti, female, 116) male and 117) female de Cassidix m. mexicanus.

\section{MEDIDAS CORPORALES:}

$\begin{array}{lrc} & \text { Macho } & \text { Hembras } \\ \text { Longitud de la cabeza } & 0,356 & 0,367-0,375 \\ \text { Anchura preantenal } & 0,292 & 0,277-0,330 \\ \text { Anchura temporal } & 0,356 & 0,334-0,390 \\ \text { Longitud del protórax } & 0,157 & 0,135-0,150 \\ \text { Anchura del protórax } & 0,240 & 0,217-0,232 \\ \text { Longitud del pterotórax } & 0,169 & 0,157-0,195 \\ \text { Anchura del pterotórax } & 0,363 & 0,330-0,401 \\ \text { Longitud del abdomen } & 0,900 & 0,975-1,095 \\ \text { Anchura del abdomen } & 0,495 & 0,409-0,532 \\ \text { Longitud total } & 1,549 & 1,605-1,794\end{array}$

HoSPEDAdOR TIPO: Cassidix mexicanus major (Vieillot, 1819).

OTRO HOSPEDADOR: Cassidix mexicanus mexicanus (Gmelin, 1788).
OBSERVACIONES: las pequeñas diferencias observadas en el margen preantenal de la hembra procedente de C. m. mexicanus son debidas a un pequeño colapsamiento de esta área durante el proceso de montaje, hecho frecuente en muchas preparaciones efectuadas por M.A. Carriker Jr. que hemos tenido oportunidad de estudiar. Hecho semejante acontece con los paraterguitos, que aparecen como muy anchos, debido a que están desplazados hacia el abdomen, apareciendo entonces totalmente distendidos. Este mismo ejemplar muestra una anomalía que abarca a los terguitos y paraterguitos V-VIII del lado izquierdo (Fig. 117).

Brueelia mimas $\mathrm{sp} . \mathrm{n}$.

(Figs. 87 a 90, 97, 105, 120 y 123)

Material EXAminAdo: Holotipo $\sigma^{x}$, Alotipo $\&$ y $70^{x} \sigma^{x}$ y 9 ㅇ $ᄋ$, Paratipos, sobre su hospedador tipo, partido Magdalena, prov. Buenos Aires, Argentina (MLP y KCE); $10^{7}$ y 3 우 우, Paratipos, mismo hospedador, Oliden, Buenos Aires, Argentina, 9-X-1972 (ACC); 17 ninfas, varias localidades de la prov. de Buenos Aires, Argentina; $200^{\top} 0^{\pi}$ y 20 우 $ᄋ$, partido Magdalena, prov. Buenos Aires, Argentina, 1985.

\section{DESCRIPCIÓN}

Macho: aspecto general muy característico, corto y robusto (Fig. 90). Cabeza anchamente suboval; borde preantenal convexo, casi parabólico. Carena marginal no espesada, apenas ondulada en su margen interno, con su mitad interna pigmentada, extendiéndose esta pigmentación algo hacia el disco cefálico. No se observan con claridad las inserciones de los músculos cibariales. Mácula del borde pulvinar de la sutura frontoclipeal ocupando casi la mitad de su longitud. Área nodal de la sutura frontoclipeal fuertemente oscurecida, aclarándose algo hacia la zona genal. Área subgenal y suturas hipostomal, occipital y postoccipital moderadamente pigmentadas. Carena temporal débilmente pigmentada en $2 / 3$ de su extensión. Apodemas pro y mesotorácicos moderadamente desarrollados y pigmentados. Pterotórax con una pequeña mácula en su margen posterior, desplazada hacia el borde externo. Placa mesosternal pequeña, piriforme, metasternal subrectangular, con sus márgenes laterales algo excavados. Terguito II despigmentado; III-IV con una pequeña marginación en su borde superior; V-VII con marginación anterior y posterior; VIII con marginación posterior, apenas insinuada en IX. Terguitos V-VII con una seta postespiracular larga y una accesoria mediana; terguitos V-VIII con una pequeña seta sutural; VI con 2-4 y 

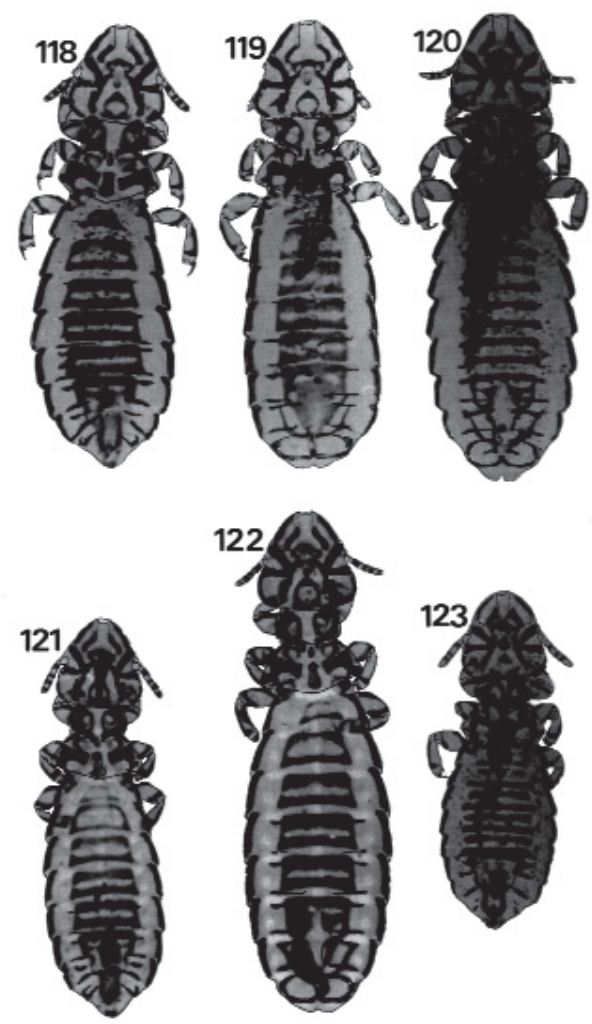

Figs. 118-123.- Habitus de 118) Brueelia ornatissima, macho y 119) hembra; 120) B. mimas, hembra y 123) macho; 121) $B$. emersoni, macho y 122) hembra.

Figs. 118-123.- Habitus of 118) Brueelia ornatissima, male and 119) female; 120) B. mimas, female and 123) male; 121) B. emersoni, male and 122) female.

VII con 3-6 setas posteriores pequeñas. Quetotaxia paratergal: II, 0; III, 1; IV-VIII, 2. Esternitos: II-VI con sus porciones anterior y posterior separadas; todos ellos muy transversos; placa subgenital con una enorme fenestra central, perdiéndose sus límites posteriores. Genitalia (Fig. 105): placa basal ancha, muy cóncava lateralmente; parámeros pigmentados, largos; escleritos laterales del complejo endomeral con su borde posterior con una hilera de unos seis tubérculos pequeños, y unas tres hileras incompletas de tubérculos en su cara inferior; longitud máxima 0,181-0,199, anchura máxima 0,0870,090 .

Hembra: como en la figura 87. Aspecto general semejante al del macho, difiriendo en tamaño, medidas, terminalia y quetotaxia abdominal. Quetotaxia paratergal: II, 0; III, 1-2; IV-VIII, 2. Placa subgenital (Fig. 97) con amplia fenestra cen-

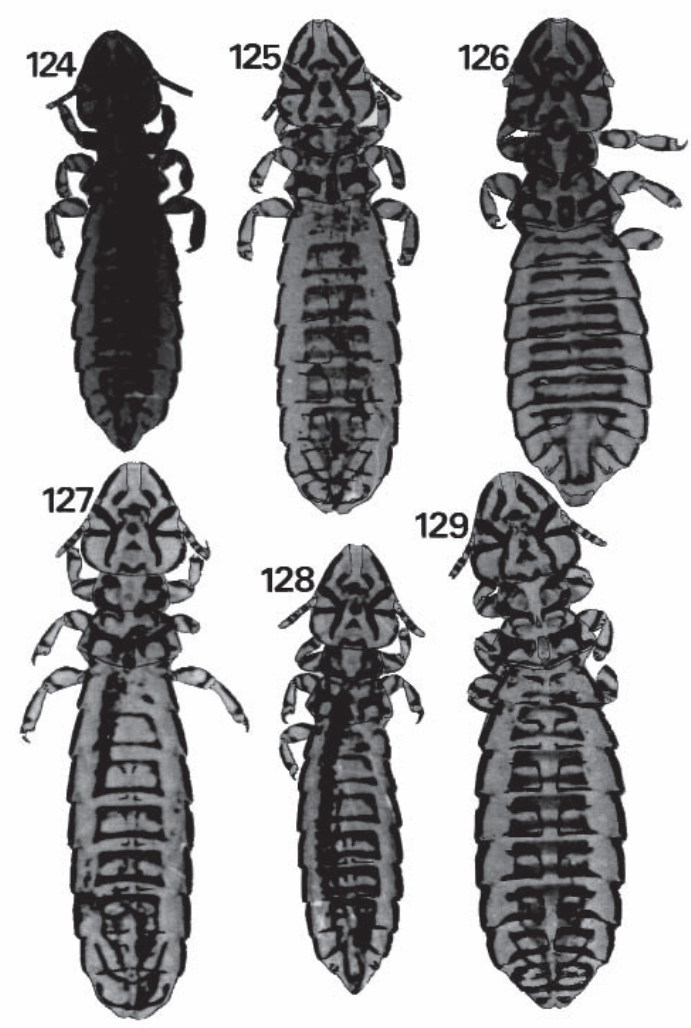

Figs. 124-129.- Habitus de 124) Brueelia bonariensis, macho y 125) hembra; 126) B. mirabile, macho; 127) B. badia, hembra y 128) macho; 129) B. marcoi, hembra.

Figs. 124-129.- Habitus of 124) Brueelia bonariensis, male and 125) female; 126) B. mirabile, male; 127) B. badia, female and 128) male; 129) B. marcoi, female.

tral alargada, y dos fenestras a cada lado, de las que la superior es más transversa. Vulva (Fig. 89) con 6-7 setas cortas espiniformes y una delgada a cada lado, y una hilera inferior de cuatro setas delgadas a cada lado. Gonapófisis con dos setas más o menos gruesas, pudiendo existir una tercera, delgada.

\section{MEDIDAS CORPORALES:}

$\begin{array}{lcc}\text { Longitud de la cabeza } & \text { Machos } & \text { Hembras } \\ \text { Anchura preantenal } & 0,322-0,345 & 0,375-0,390 \\ \text { Anchura temporal } & 0,265-0,283 & 0,307-0,315 \\ \text { Longitud del protórax } & 0,310-0,328 & 0,367-0,375 \\ \text { Anchura del protórax } & 0,210-0,135 & 0,135-0,142 \\ \text { Longitud del pterotórax } & 0,172-0,180 & 0,232-0,244 \\ \text { Anchura del pterotórax } & 0,337-0,345 & 0,356-0,210 \\ \text { Longitud del abdomen } & 0,727-0,772 & 0,997-1,140 \\ \text { Anchura del abdomen } & 0,435-0,465 & 0,525-0,555 \\ \text { Longitud total } & 1,322-1,379 & 1,662-1,776\end{array}$


HOSPEDADOR TIPO: Pseudoleistes virescens (Vieillot, 1819).

OBSERVACIONES: especie fácilmente reconocible por su silueta corta y robusta, carenas marginal y temporal débilmente pigmentadas, forma de la cabeza y característica de los esternitos.

\section{AGRADECIMIENTOS}

Deseamos expresar aquí nuestro agradecimiento al Dr. Oliver S. Flint, del AMNH, y al malogrado Dr. Kary C. Emerson de Sanibel, Florida, por el generoso préstamo de numerosos ejemplares utilizados en el presente estudio.

\section{Referencias}

Amadon, D., 1966. The superspecies concept. Syst. Zool., 5: 245-249.

CARRIKER, M.A. Jr., 1954. Report on a collection of Mallophaga, largely Mexican (Part I-cont'd). Florida Entomol., 37(3):191-207.

CARriKer, M.A. Jr., 1957. Notes on some of the Vernon L. Kellogg types of Mallophaga. Microentomology, 22(5): 95-110.

Cicchino, A.C., 1986. Mallophaga Neartica I. Una nueva especie del género Brueelia Keler, 1936 (Mallophaga-Philopteridae), probablemente parásita de Sturnella neglecta Audubon, 1844 (Aves, Passeriformes, Emberizidae, Icterinae). Rev. Soc. Entomol. Arg., 44(1): 85-89.

Cicchino, A.C., 1990. Contribución al conocimiento de los malófagos argentinos XX. Primera adición a la revisión preliminar de las especies del género Brueelia Keler, 1936 (Mallophaga: Philopteridae) parásitas de Icterinae (Aves, Passeriformes, Emberizidae). Spheniscus, 8: 21-26.

ClAy, T., 1951. An introduction to a classification on the avia Ischnocera. Part I. Trans. Entomol. Soc. London, 102: 171-194.

EICHLER, W., 1938. Bizarrifrons nov. gen., eine bemerkenswerte asymmetrische Federlingsgattung von Icteriden. (Betrauchtungen über morphologische Besonderheiten bei Mallophagen. I). Zool. Anz., 124(9-10): 225-236.

EMERson, K.C., 1960. Notes on the Osborn Mallophaga types. Proc. Biol. Soc. Washington, 73: 155-166.

EMERSON, K.C., 1972. Checklist of the Mallophaga of North America (North of Mexico). Utah, USA. Pt. I, 200 pp., Pt. IV, 216 pp.
FriedmanN, H., 1963. Host relations of the Parasitic Cowbirds. U.S. Natl. Mus. Bull., 233: 1-275.

Giebel, C.H.R., 1866. Die im Zoologischen Museum der Universität Halle sufgestellten Epizoen nebst Beobachtungen uber dieselben. Z. Naturwiss. Halle, 28(11-12): 353-397.

GeIst, R.M., 1935. Additional Mallophaga from Ohio birds. Ohio J. Sci., 35: 93-100.

Hopkins, G.H.L. \& Clay, T., 1952. Checklist of Mallophaga. British Museum (Natural History). London. 362 pp.

KellogG, V.L., 1896. New mallophaga, II. From land birds, together with an account of the Mallophagous mouth-parts. Proc. California Acad. Sci., 6: 431-548.

KellogG, V.L., 1899. Mallophaga from birds of Panama, Baja California and Alaska. Occas. Pap. California Acad. Sci., 6: 3-52.

OsBorN, H., 1896. Insect infesting domestic animals. Chapter V, Suborder Mallophaga. Birds Lice. Bull. U.S. Dep. Agric. (Bur. Entomol.) (n.s.), 5: 189-249.

Piaget, E., 1880. Les Pédiculines. Essai monographique. E.J. Brill. Leiden. XXXIX+714 pp.

SHORT, L.L. JR., 1968. Sympatry of red breasted meadowlarks in Argentina, and the taxonomy of meadowlarks (Aves: Leistes, Pezistes and Sturnella). Am. Mus. Novit., 2349: 1-30.

Sibley, C.G., Ahlquist, J.E. \& Monroe, B.L. JR., 1988. A classification of the living birds of the wolrd based on DNA-DNA hybridization studies. Auk, 105(3): 409-423.

Stafford, E.W., 1943. Algunos Mallophaga Venezolanos (Some Venezuelan Mallophaga). Bol. Entomol. Venezol., 2: 35-58.

Symmons, S., 1952. Comparative anatomy of the Mallophagan head. Trans. Zool. Soc. London, 27[pt. IV(1)]: 346-349.

Teel, P.D., Fletwood, S.C., Hopkins, S.W. \& Cruz, D., 1988. Ectoparasites of Eastern and Western meadowlarks from the Rio Grande Plains of South Texas. $J$. Med. Entomol., 25(1): 32-35. 